\title{
THE PEATLAND/ICE AGE HYPOTHESIS REVISED, ADDING A POSSIBLE GLACIAL PULSE TRIGGER.
}

\author{
BY \\ LARS G. FRANZÉN \\ Department of Earth Sciences, Göteborg University, \\ and \\ ROGER A. CROPP \\ Centre for Environmental Systems Research \\ Griffith University
}

\begin{abstract}
Carbon sequestering in peatlands is believed to be a major climate regulating mechanisms throughout the late Phanerozoic. Since plant life first evolved on land, peatlands have been significant carbon sinks, which could explain significant parts of the large variations in the atmospheric carbon dioxide observed in various records. The result is peat in different degrees of metamorphosis i.e. lignite, hard coal and graphite. During phases of extensive glaciations such as the 330-240 MY Pangea Ice Age atmospheric carbon dioxide was critically low (e.g. Berner and Kothavala 2001). This pattern repeats itself during the Pleistocene where carbon dioxide oscillates with an amplitude of c. 200-300 ppmv. This paper suggests that the ice age cycles during the Pleistocene are generated by the interglacial growth of peatlands and the subsequent sequestering of carbon into this terrestrial pool. The final initiation of ice age pulses towards the end of interglacials on the other hand is attributed to the cyclic influx of cosmic dust to the Earth surface, which in turn regulates cloud formation and the incoming shortwave radiation. These shorter cycles have a frequency of c. 1000-1250 years and might be connected to sunspot or other low frequency solar variations. In a wider context the ice age cycling could be regarded as an interplay between terrestrial life on the high latitudes of the northern hemisphere and the marine subsurface life in the south-east.

If the results presented here are correct the present global warming might just be the early part of a new warm period such as the Bronze Age and the Roman and Medieval Warms. This could be caused by the entrance into just another phase of decreasing influx rates of cosmic dust. The increasing concentrations of atmospheric carbon dioxide might have contributed to this warming but most important of all, it might temporarily have saved us from a new Ice Age Pulse.
\end{abstract}

\section{Introduction}

"Even if the bog Komosse is not of the same size as the bog Storemosse in Käfsjö and Aker parishes, it still was a more than usually dreary sight, that appeared to my eyes when I, on a dark and rainy day stood at the north-eastern edge of this wasteland, prepared to take a walk across it. I have had the opportunity to see many raised bogs, equal in size to Komosse, and I have often been attracted by their waste and wild beauty. I have admired the wonderful display of colours of the mires of northern Sweden on a bright summer day, which is beyond all description; I have actually been stunned at the sight of a heather bog, glowing like a sea of purple at sunset - but I have never seen a mire having a, so to speak, scoundrelly appearance as this one. Lacking all trees worth speaking of, with the vast grey-brown surface frequently broken by holes and grooves filled with black mud and numerous ponds in which water a lead grey sky was reflected, without sign of advanced animal life, it just lay there like an enormous, repulsive polyp, stretching out its dreadful arms and intruding in all directions. It is an open, constantly fretting cancer wound to its district and the private enterprise stands perplexed and vain against this evil spreading over its surroundings. The warm-hearted person, now deceased, that once proposed that the government should take immediate steps to drain all larger bogs, had he needed new impulses to raise this question again-indeed he couldn't have got them better than at the edge of Komosse." (Robert Tolf 1893) 
Komosse is one of the largest remaining virgin bog complexes in Europe is also one of the most studied, from different point of views including vegetation (e.g. Osvald 1923) and hydrology (e.g. Johansson 1976).

Over the last 20 years, since the first author presented his thesis on the peat resources of Sweden (Franzén 1985), the main research focus has been put on peatlands' role in the global carbon cycle. Many articles have been presented on this, both in national and international press (Franzén 1992-2006). The outcome of these studies is (I): a new theory for the cyclic appearance of glacials and interglacials throughout the Pleistocene and (II): a theory to explain rapid climate shifts e.g. during the Holocene also providing a mechanism for the onset of new glacial pulses at the end of interglacials. In the following we will describe the two different theories separately starting with the Peatland/Ice Age Hypothesis.

\section{The Peatland/Ice Age Hypothesis}

The first author has often considered peatlands as non-static elements in nature. The old sayings that peatlands inundate their surroundings came from forest people and farmers that had struggled against this "plague" for centuries. Even if well-know scientists such as von Post (1927) and Malmström (1932) had denied this and put out the alarm bell by declaring peatlands as "dead" regarding lateral growth it was hard to accept this as a simple fact. The first embryo to the whole idea of dynamic peatlands arose during the thesis work (Franzén 1985) when it became obvious that most mires' stratigraphical cross-sections are lens shaped i.e. the deepest parts were in the centre and they were thinning out towards the margins. More than 18500 peatland cross-sections from various road and railroad construction archives in Sweden were studied during this work and they all conformed, with some minor deviations, to the same basic elliptic form (Fig. 1). From this observation insight grew that most peatlands must have been initiated in a very small central area and eventually have expanded from that site to occupy larger and larger parts of the surrounding mineral grounds. The only exceptions were the relatively few types of mire that had started as lakes which had eventually been terrestrialized and developed differently than the ones with a "drier" birth. Assuming that the vertical peat accumulation would be the same over the entire peatland surface, the thinner peat layers towards the margin must be younger than the thicker parts in the centre, and hence the mire must have been spreading laterally from the centre towards the margins. With this it stood clear that peatlands are dynamic systems with the ability to grow both vertically and laterally, and that by the latter mechanism they were increasing their areal extent in a quadratic mode. There was not any clear evidence that this expansion had ceased, except in places where protective drainage had temporary halted this, or where they had found their final station against each other or towards steep terrain hindrances. 


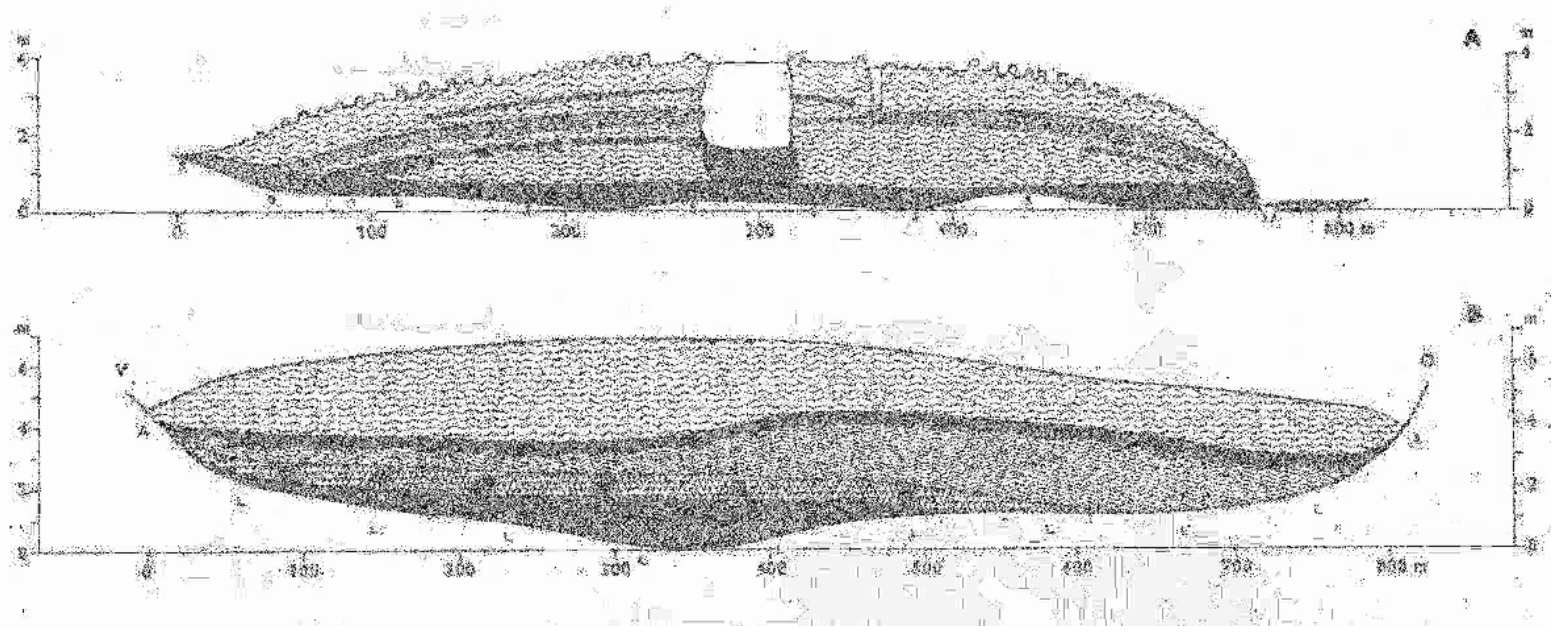

Fig 1. Two typical raised bog sections showing their general elliptical shape. A-ombrogenous bog, Bterrestrialization bog (Redrawn after Lundqvist 1955). The various shadings in the upper parts of the stratigraphies principally show various grades of bog peat decomposition.

The main point in the hypothesis is hence that peatlands do not only grow vertically but also horizontally. Whereas the vertical accumulation is accepted and well confirmed, the lateral growth has been a matter of debate for over a century. The two main opposers to this during the hottest year of debate were von Post and Malmström as mentioned above. However, with the access of ${ }^{14} \mathrm{C}$-datings it was later made possible to confirm the actual existence of a quite rapid growth of peatlands over the surrounding mineral grounds, caused by marginal paludification. Some studies have measured rates of annual radial spread in metres per year (e.g. Aaby 1990, Kuzmin 1994) whereas others have claimed a more moderate growth averaging around $10 \mathrm{~cm}$ per annum (Almquist-Jacobsen and Foster 1995, Lode et al. 2001, Lode 2002). Korhola (1992, 1994, 1995), from a Finnish study, concluded that at certain periods in mire history ".. the mire front advancing several metres a year indicating that mire ecosystems are by nature exceptionally expansive elements." To compare these observations with south Swedish conditions, a similar investigation was performed in the bog complex of Komosse. With the aid of 53 calibrated (Stuiver and Reimer 1993) ${ }^{14}$ C-datings (Ua-12461-12464, Ua12589-12613 \& Ua14061-14084) of basal peat layers a mean lateral growth of $10.6 \mathrm{~cm} /$ year could be calculated, since the mire was initiated some 7500 years ago (Franzén 2002). The annual lateral growth rates plotted in 500-year intervals are shown in Figure 2. Sampling section location coordinates are given in Table 1 (5a, 5b) and may be viewed e.g. in Google Earth ${ }^{\mathrm{TM}}$.

The new hypothesis on climate regulation by peatland growth was introduced in 1994 (Franzén 1994). This first paper was followed by a more thorough modelling of the basic principles in 1996 (Franzén et al. 1996) and a further paper in 1997 (Franzén, 1997). Klinger $(1990,1991)$ independently presented similar ideas but with a somewhat different approach, and a common paper was published in 1996 (Klinger et al. 1996). The Komosse datings of above were made after the first introduction of the hypothesis. 


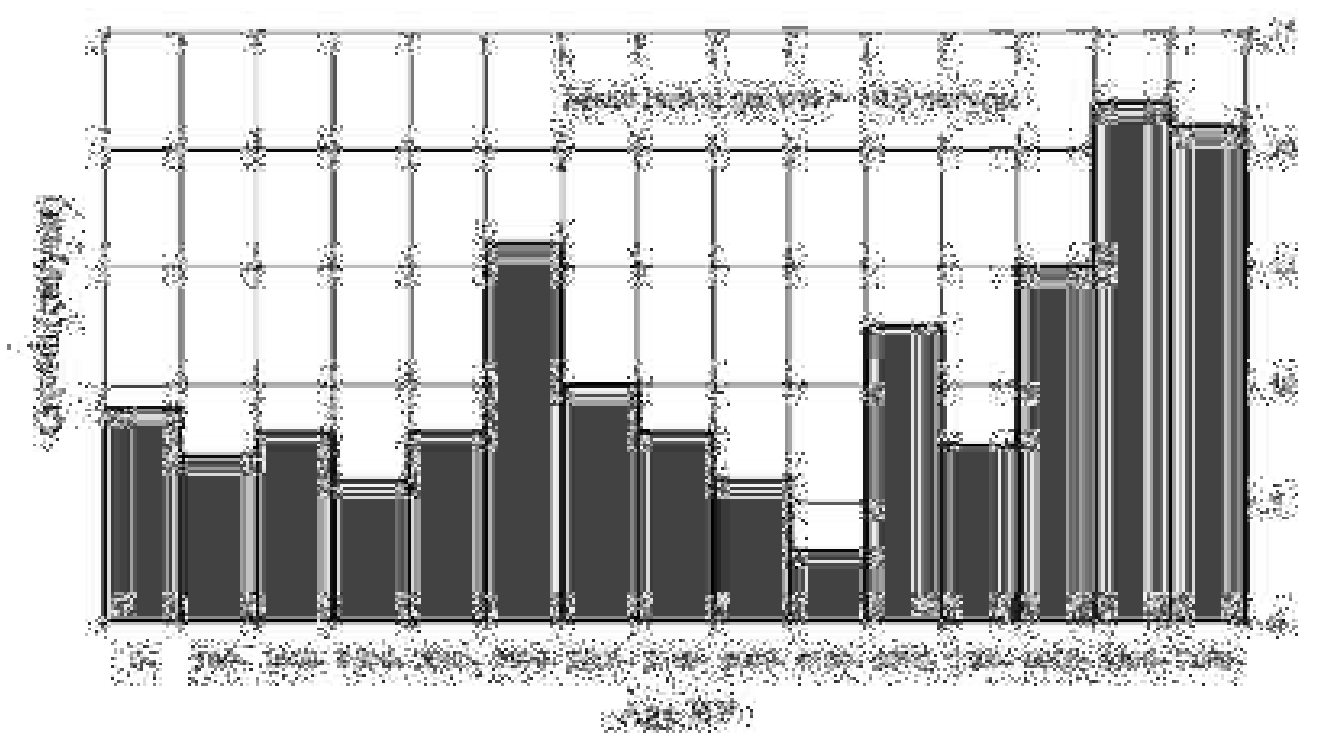

Fig. 2. Annual lateral growth at Karsbomossen, Komosse raised bog complex, as calculated from $53{ }^{14} \mathrm{C}$-datings of basal peat.

\section{The Peatland/Ice Age Hypothesis}

The Peatland/Ice Age Hypothesis postulates that an ice age cycle is divided into five distinctive phases or stages (Fig. 3) i.e.:

1/ Glacial phase

2/ Deglaciation phase

3/ Vegetation reestablishment phase

4/ Mire phase

$5 /$ glacial Initiation phase

All of these stages are interconnected to the development of the atmospheric concentration of carbon dioxide and methane in one way or the other, as it has been described from the Antarctic and Arctic Ice core investigations. Beside the five major phases there are three points that are of importance for the further discussion: the Fen/Bog transition point during the Mire phase, the Carbon Dioxide Break Point $\left(\mathrm{CO}_{2} \mathrm{BP}\right)$ at the end of Mire phase and Glacial Pulse Initiation Point (GPIP) at the transition between the glacial Initiation phase and the Glacial phase.

The present global distribution of peatlands reveals a striking correlation with areas intermittently subjected to glaciation (Franzén 1994). In fact, more than 90 per cent of the Earth's peatlands are found at latitudes greater than $45^{\circ} \mathrm{N} / \mathrm{S}$. From a geomorphologic point of comparison the extent of peatlands equals most areas where lakes are common. Peatlands are normally initiated in moist depressions in hummocky moraines, glacially eroded bedrock areas (i.e. exhumed deep-weathering landscapes) and other hydrological closed basins which are normally associated with glacial activity. Contrasting this are true fluvial landscape types which are not generally suitable for peatland formation. Other important conditions for the further development of peatlands, once initiated, are relatively impermeable subsoil and plain lands over which they can advance during lateral growth. Naturally, lateral growth is stopped where mires meet, or is slowed in steep terrain gradients (Franzén 1994). 
Geografiska Annaler Special Issue for SL - Lars Franzén and Roger Cropp

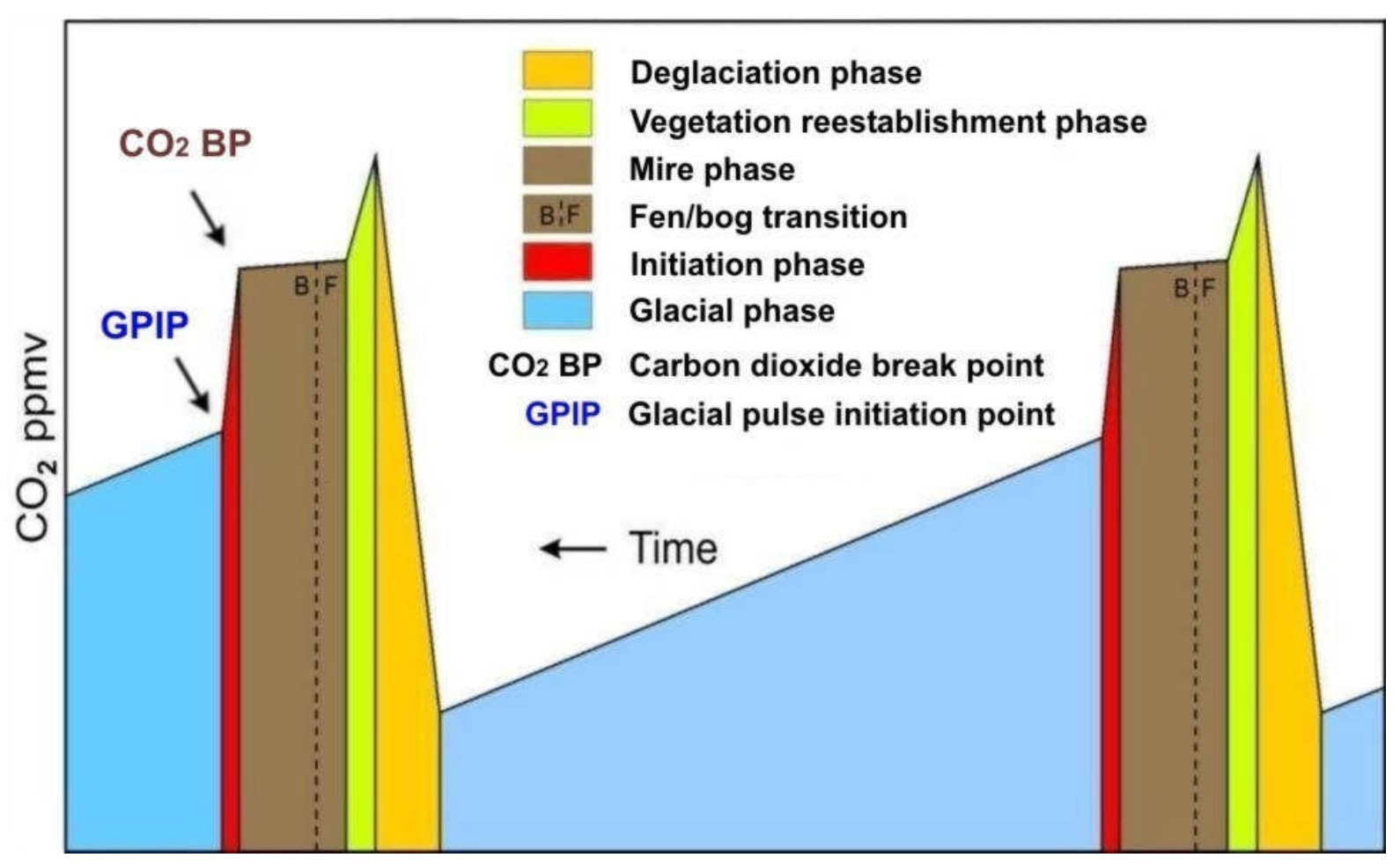

Fig. 3. The Peatland/Ice Age Hypothesis - a schematic overview.
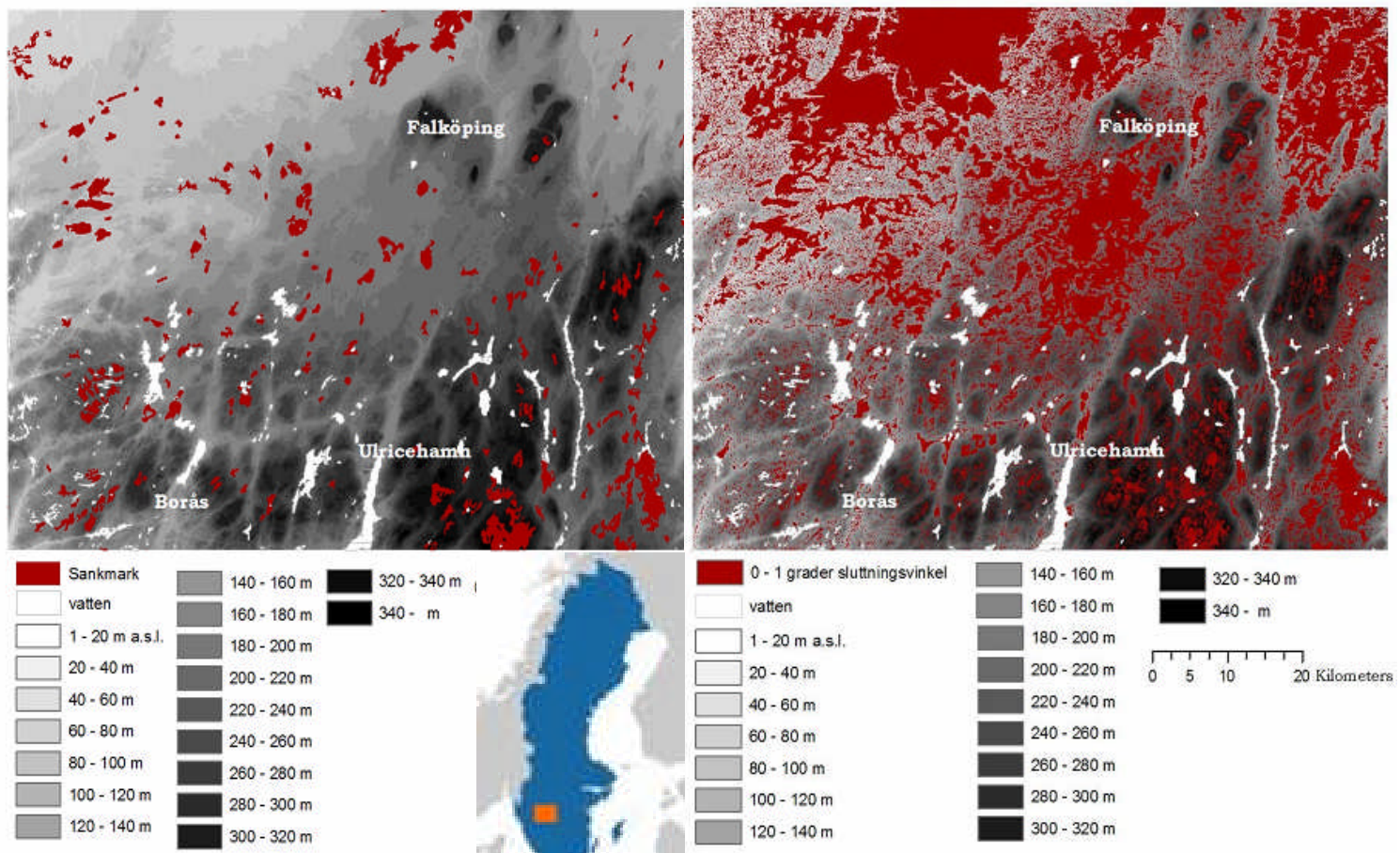

Fig. 4. Present (left) and potential (right) area covered by peatlands (red) using GIS techniques. Potentially peat covered areas represent terrain with a slope angle less than $1^{\circ}$. White areas are lakes. (From Seftigen 2007).

A check of topographical maps of southern Sweden for landscapes suitable for peatland coverage revealed that far more land is potentially able to be paludified in this way than is 
covered by peatlands today. As a pilot project a test area in southern Västergötland, SW Sweden (Fig. 4) was investigated (Seftigen 2007) using data from the Swedish National Library of Digital Maps and ArcGIS 9.1/ArcMap software. Elevation data were transferred into slope angle and areas with an inclination of $\leq 1^{\circ}$ calculated. The results showed that the investigated area a had a potential to hold a 5-6 fold increase of peatlands compared to the existing peatland area when looking at terrain forms alone according to criteria used by Franzén (1985).

The hypothesis recognises that the carbon sink due to peatlands, after a certain period of postglacial lateral growth, would reach a point where this sink would exceed the bottle-neck value of deep ocean/surface ocean compensation i.e. more carbon dioxide would be retracted from the atmosphere into the peatland carbon sink than what could be compensated by flows from the deep ocean reservoir. A simple model for carbon exchange showed that at this point atmospheric carbon dioxide would drop rapidly below a critical "threshold" level which would be too low to maintain a sufficiently large greenhouse effect to prevent re-glaciation (Franzén et al. 1996). Peatland lateral growth would hence lead into an unstable Initiation phase in which a small disturbance might subsequently lead to a new ice age pulse, at a point that I have called the Glacial Pulse Initiation Point (GPIP). The different phases are now discussed in detail, starting with the Glacial phase.

\section{Glacial phase}

The generally accepted idea some 40 years ago was that widespread glaciation starts slowly with mountain glaciation, followed by a relative moderate spread rate over the surrounding terrain. In such a scenario the global carbon cycle would adapt to the development of ice and not evidence any rapid changes. However, in the mid 1970-s the tabloid press was filled with alarms of an impending Ice Age, which threatened if the right criteria were fulfilled. The cause of this alarm was an article by Nigel Calder (1974) in which it was suggested that glaciations didn't start from above (read: mountains) but from below (read: by instant and durable snow cover at low altitudes). The hypothesis presented here postulates that the glacial pulse starts with such a Snowblitz, a result of which is that all organic material, living, and accumulated dead (peat), is rapidly buried under snow and ice. There it remains during the whole of the ice age cycle due to cold based glacial conditions. During the glacial phase atmospheric $\mathrm{CO}_{2}$ levels decline as the gradually cooling ocean waters store more $\mathrm{CO}_{2}$ in accordance with Henry's Law.

The evidence for cold based ice has been mainly provided by the re-evaluation of the effectiveness of glacial erosion in plain areas such as Finland, the northern interior of Sweden and the central plains of south Sweden, where Pre-Pleistocene weathering forms and deposits still remain more or less unaffected despite the numerous glaciations which have come and gone (e.g. Olvmo et al. 2005). In the Snowblitz scenario a vast amount of organic material is deep frozen for the duration of the glaciation and is only exposed during the final stages when warm-based ice and subsequent basal slip initiate transportation towards the ice margin. Much of this material is also exposed gradually as the ice-front retreats. The mires, supported by a persistent high water table during the interglacial, would be dehydrated by ice pressure and the peat then subject to rapid oxidation and micro-biological decomposition when exposed to oxygen-rich melt water while still under the melting ice and later under the direct influence of the atmosphere. The same goes for all other organic substances including timber from buried forests and all other parts of the Snowblitzed ecosystems prevailing before glacial initiation. 


\section{Deglaciation phase}

The deglaciation mechanisms are more complex, and to my knowledge no solid explanation exists for why ice age pulses end. One theory is that when ice caps have reached a certain extension they are so wide and high that air masses with nourishing precipitation can no longer reach the interior, which leads to glacier starvation and eventual death. Another theory proposes that when ice caps have reached a certain thickness over the European and North American continents the landmasses are lowered so much by isostasis that the ice caps starts calving beyond control and are emptied that way. A third theory, that is consistent with the PELIAH hypothesis is the possibility of ice caps being so thick that finally they switch over from cold based to warm based from mere pressure. From this moment on, the basal slip would fulfil the required emptying mechanism of base material described above and hence a transport of organic material to the ice margins where it oxidizes into carbon dioxide. The reaction would be self-perpetuating (that is, it would generate a positive feedback) with increasingly high concentrations of atmospheric carbon dioxide, and with that increased greenhouse effect and rising temperatures as the ice front retreats. The condition for this latter proposal is that carbon dioxide takes a lead over temperature and not vice versa. Subglacial organic-rich soils would be expected to contain large amounts of methane from anaerobic activity. Methane stored in northerly fenland peats and tundra soils during the preceding interglacial would also be released as a result of this process and would subsequently be oxidized into $\mathrm{CO}_{2}$. A fourth more speculative theory of rapid deglaciation is the eustatic shoaling of sedimentary methane gradients during LGM's and massive releases of methane from gas hydrate dissociation of basin sediments (Kennett et al. 2000).

\section{Vegetation reestablishment phase}

Deglaciation is followed, eventually, by the re-establishment of terrestrial ecosystems which draws down large amounts of $\mathrm{CO}_{2}$ from the atmosphere. As the plant biomass increases and the globe warms new atmosphere/ocean $\mathrm{CO}_{2}$ equilibriums are established.

\section{Mire phase}

New peatlands start to form, more or less immediately after deglaciation, in moist depressions created in the landscapes which have been given a glacial signature. The first mires to form are minerotrophic fens that are high producers of methane. One would hence expect higher atmospheric concentrations of $\mathrm{CH}_{4}$ at the earlier stages of an interglacial than later on when large proportions of these fens have metamorphosed into drier mire types with low methane production. The timing of this transformation is not predictable in the mire development but occurs during interglacial events and is influenced by periods of high precipitation, or other climatic factors, favouring the transition from fen to bog (e.g. Granlund 1932).

The lateral growth of peatlands basically means that the area of a given idealized mire increases with the quadratic function i.e.:

$$
A_{n}=r_{n}^{2} \times \pi
$$


where $r_{n}$ is the radius of the mire after $n$ years and $A_{n}$ is the area of the mire. The amount of carbon drawn down from the atmosphere by a mire as it grows is proportional to the increase in the volume of the mire. However, as the vertical growth of mires is generally much slower than the lateral growth, resulting in the "lens" shape of most mires (Fig. 1), the peat carbon store increases as a quasi-cubic function.

$$
V_{n}=r_{n}^{2} \times \pi \times \delta h_{n}
$$

where $\boldsymbol{\delta} \boldsymbol{h}_{\boldsymbol{n}}$ is the annual vertical component of peatland growth and $V_{n}$ is the volume of mire added in year $n$.

From the PELIAH point of view, the circle is closing again with gradually growing peatlands spreading like "cancer" in the terrain. The cancer could be given a Latin name i.e. the genus of Sphagnum. Sphagnum is the most common plant of mid and high latitude mires and the various species occupy all mire niches, from the richest of fens to the poorest of bog communities. Sphagna individuals are also some of the most numerous plant species in the world, and in addition among the organisms with the longest life span on Earth. Given the right environmental conditions an individual bog Sphagnum plant might have developed out of a spore just at the start of the mire phase.

\section{Initiation phase}

Towards the end of an idealized interglacial, not interfered with by any human activity, the total peatland area might have reached an extent such that it significantly reduces the contribution of carbon dioxide to the greenhouse effect. In the Peatland/Ice age hypothesis we reach the "Carbon Dioxide Break Point" (Fig. 3, $\mathrm{CO}_{2} \mathrm{BP}$ ) after which atmospheric carbon dioxide decreases rapidly. Whereas current debate on atmospheric carbon dioxide is focussed on increasing concentration; relatively little attention has been paid to the importance of reducing contemporary levels. Manabe and Bryan (1985) presented a model for $\mathrm{CO}_{2}$ concentrations' influence on the world's surface temperatures (by latitude) at different concentrations (Fig. 5). The most dramatic results from this model are not the temperature increases that would occur with rising $\mathrm{CO}_{2}$ levels, but rather the temperature effects of reducing levels. Whereas a doubling of $\mathrm{CO}_{2}$ from the pre-industrial 270 ppmv would only raise surface temperatures $3-4^{\circ} \mathrm{C}$ at latitude $60^{\circ}$ for example, a similar lowering to half of the pre-industrial values would decrease temperatures by more that $20^{\circ} \mathrm{C}$. The PELIAH hypothesis does not therefore oppose the current paradigm that atmospheric carbon dioxide influences global temperatures, but notes that the effects on temperature of the upper scale of contemporary concentrations is much less significant than that of decreasing atmospheric concentrations from current levels. 


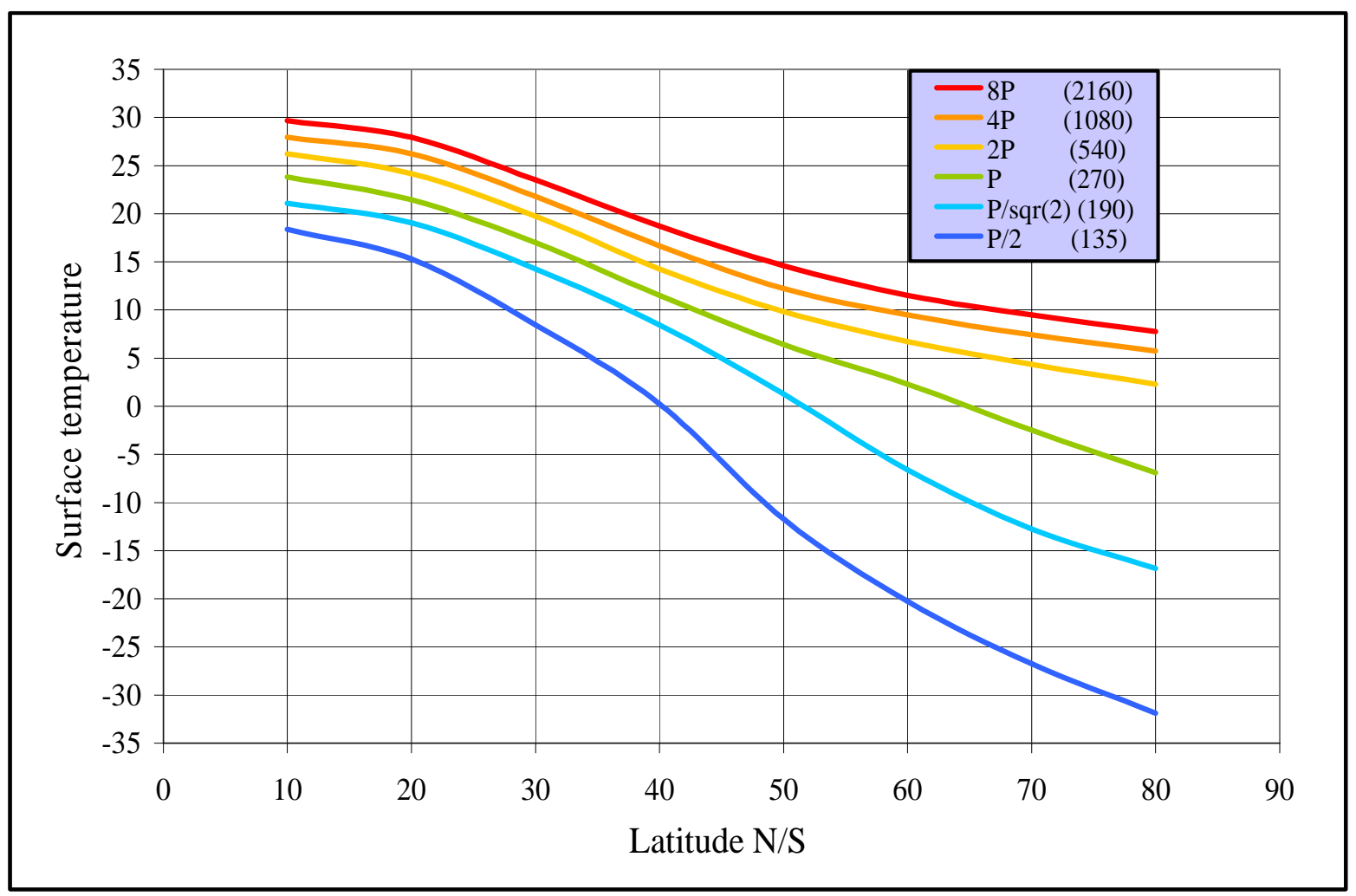

Fig. 5. A model for $\mathrm{CO}_{2}$ concentrations' influence on the world's surface temperatures (by latitude) at different concentrations (0.5-8x preindustrial). Reworked after Manabe and Bryan (1985)

Examination of the evolution of carbon dioxide over time in Antarctic ice cores suggests that there exists a "knick point" at the start of ice ages, with $\mathrm{CO}_{2}$ concentrations at about 240-260 ppmv. Putting these bracketed values into Manabe and Bryan's model we find that surface temperatures at the example latitude of $60^{\circ}$ would fall $0.6,1.4$ and $2.2^{\circ} \mathrm{C}$ at 260,250 and 240 ppmv respectively. The temperature response at higher latitudes would be even greater. Even if glaciation could start spontaneously from temperature drop alone, a critical initiating push over the edge would certainly help. Dust veils resulting from volcanic eruptions are among the obvious causes suggested for such triggers. Over the year following the volcanic eruption of Mount Tambora in Sumbawa, Indonesia, on 10th April 1815, for instance, heavy ash-fall filled the air across the globe, preventing sunrays from reaching the Earth. The resulting frost and rains devastated crops and caused the "Year without summer". Another good example is the Mt Pinatubo eruption of 1991 which was being blamed for the global temperature drop of the early 1990s. Even if dust veils from volcanic eruptions would only have a temporary cooling effect (a couple of years until the aerosols fall out of the atmosphere) and then a substantial, long-term (decades) warming effect due to the increased atmospheric carbon dioxide from the eruptions, a relative short period of substantial volcanic aerosols injection into the atmosphere might cause enough dimming of incoming solar radiation to permit a persistive snow cover in high latitudes over a few years. The subsequent albedo effect might then lead to a global cooling strong enough to push Earth into a new ice age. Cosmic dust is another good candidate which has been suggested e.g. by Clube and Napier (1990). In the Peatland/Ice Age hypothesis we have now reached the "Glacial Pulse Initiation Point" (Fig. 4, GPIP). The following part of this paper proposes a new candidate for the initiation of ice age pulses, when peatlands have fulfilled their preparatory task described above. 


\section{The Glacial Pulse Trigger}

The last 10 years or so has been a search for a mechanism that would be sufficiently strong to trigger an ice age pulse once carbon dioxide has been lowered to the critical values described above. In this quest peat stratigraphies have been studied, preferably mires with not too strongly decomposed peat, in a large number of places around the world e.g. Sweden, Norway, Ireland, Tierra del Fuego, Siberia and Tibet.

With the knowledge of a very variable climate during the Holocene, with rather rapid shifts between extremes, the question arose if peatlands themselves might have the potential of bearing some unrevealed secrets in their stratigraphies. Analogous with glaciers and sedimentary records, peat bogs have an annual accumulation of matter and objects deposited upon the peat surface are buried along with dead plant remains. In contrast to many other sedimentary records peatlands lack bioturbation, that is, most peatlands (and in particular the ombrotrophic sites) lack most kinds of disturbing animal life. Hence, the peat record does not suffer the common mixing problem, at least not regarding particles. A small downward transport of micro particles such as volcanic glass shards could be expected but rarely in the opposite direction. Dissolved matter might fluctuate with the shifts in groundwater level and a minor downward drift could be expected. The horizontal permeability of peat is many times higher than the vertical, basically because plant stems and leaves are packed upon each other like pages in a book. Bogs can also be regarded as gigantic water reservoirs where much water is retained in the specialized type of structure in Sphagnum called hyaline cells. One part of white moss nutrient strategy is to compete for the small amount of nutrient that might be contained in every drop of rain or melted flake of snow. This specialization provides an advantage when studying stored dissolved matter, especially when the peats studied are weakly decomposed and the hyaline structures are intact.

Only particulate matter was investigated in the initial phase of peat studies, looking for volcanic glass shards and other particles randomly. I soon became obvious that some of the peat samples contained microscopic black spherules but also other spherules of various transparencies and colour. A comparison between different mires in southern Sweden showed that these spherules were concentrated at certain stratigraphical levels, which were approximately correlated between the different bogs, and with other stratigraphical properties. My colleague at that time, Professor Birger Schmitz encouraged me to continue, but also suggested to make my studies more systematic. The acquisition of a new Inductively Coupled Plasma Mass Spectrometer (ICP-MS), an Agilent 7500a, at the department also opened the possibility to perform systematic geochemical studies of the peat. Since, I have collected and analysed material from 14 Swedish, three Norwegian, four Irish, five Fuegian and three Chinese Tibetan mires, mainly raised bogs. Results from 21 of the mires are presented here. The coordinates of all presented sampling sites are given in Table 1. The locations of these sites may be viewed using these coordinates with Google Earth ${ }^{\mathrm{TM}}$, for example.

Table 1. Sampling sites for the peat studies. The sites could be visited and viewed using coordinates with Google Earth ${ }^{\mathrm{TM}}$. 
Geografiska Annaler Special Issue for SL - Lars Franzén and Roger Cropp

\begin{tabular}{|c|c|c|c|c|c|}
\hline Sampling & Sampling site & Latitude & Longitude & Elevation & Elevation \\
\hline point \# & & & & feet & m a.s.l. \\
\hline & & & & & \\
\hline & SWEDEN & & & & \\
\hline 1 & Dömle mosse & $59^{\circ} 34^{\prime} 18.63 ” \mathrm{~N}$ & $13^{\circ} 25^{\prime} 58.50^{\prime \prime} \mathrm{E}$ & 202 & 62 \\
\hline 2 & Hjortemossen & $58^{\circ} 06^{\prime} 57.04^{\prime \prime} \mathrm{N}$ & $13^{\circ} 29^{\prime} 32.73^{\prime \prime} \mathrm{E}$ & 651 & 198 \\
\hline 3 & Komosse - Björnsjömossen & $57^{\circ} 41^{\prime} 46.31^{\prime \prime} \mathrm{N}$ & $13^{\circ} 40^{\prime} 59.87^{\prime \prime} \mathrm{E}$ & 1107 & 338 \\
\hline 4 & Konungsö mosse & $57^{\circ} 38^{\prime} 42.09^{\prime \prime} \mathrm{N}$ & $14^{\circ} 14^{\prime} 52.93^{\prime \prime} \mathrm{E}$ & 740 & 226 \\
\hline $5 \mathrm{a}$ & Komosse - Karsbomossen start point & $57^{\circ} 38^{\prime} 12.15^{\prime \prime} \mathrm{N}$ & $13^{\circ} 42^{\prime} 04.76^{\prime \prime} \mathrm{E}$ & 1067 & 325 \\
\hline $5 b$ & Komosse - Karsbomossen end point & $57^{\circ} 37^{\prime} 57.39^{\prime \prime} \mathrm{N}$ & 1342’36.49’"E & 1052 & 321 \\
\hline 6 & Fallamossen & $57^{\circ} 32^{\prime} 11.61^{\prime \prime} \mathrm{N}$ & 14.31'17.31'”E & 1157 & 353 \\
\hline 7 & Lyngmossen & $57^{\circ} 24^{\prime} 39.78^{\prime \prime} \mathrm{N}$ & $12^{\circ} 22^{\prime} 51.07 ’ \mathrm{E}$ & 230 & 70 \\
\hline 8 & Store mosse Öxabäck & $57^{\circ} 24^{\prime} 17.35^{\prime \prime} \mathrm{N}$ & 12॰49'51.55’"E & 399 & 122 \\
\hline 9 & Vildmossen & $57^{\circ} 20^{\prime} 46.46^{\prime \prime} \mathrm{N}$ & $15^{\circ} 02^{\prime} 48.46^{\prime \prime} \mathrm{E}$ & 759 & 231 \\
\hline 10 & Store Kävsjö mosse & $57^{\circ} 17^{\prime} 56.52^{\prime \prime} \mathrm{N}$ & 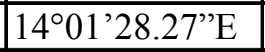 & 552 & 168 \\
\hline 11 & Gällseredsmossen & $57^{\circ} 10^{\prime} 35.20^{\prime \prime} \mathrm{N}$ & $12^{\circ} 35^{\prime} 51.10^{\prime \prime} \mathrm{E}$ & 335 & 102 \\
\hline 12 & Bråtarna & $57^{\circ} 08^{\prime} 55.63^{\prime \prime} \mathrm{N}$ & $14^{\circ} 45^{\prime} 02.94^{\prime \prime} \mathrm{E}$ & 818 & 249 \\
\hline 13 & Torstamåla fly & $56^{\circ} 44^{\prime} 48.27^{\prime \prime} \mathrm{N}$ & $15^{\circ} 36^{\prime} 05.53^{\prime \prime} \mathrm{E}$ & 549 & 167 \\
\hline \multirow[t]{2}{*}{14} & Store Mosse Kallinge & $56^{\circ} 18^{\prime} 06.28^{\prime \prime} \mathrm{N}$ & 15'19'51.41’'E & 235 & 72 \\
\hline & IRELAND (N \& Rep.) & & & & \\
\hline 15 & Fallahogy bog & $54^{\circ} 55^{\prime} 42.84^{\prime \prime} \mathrm{N}$ & $06^{\circ} 31^{\prime} 58.94^{\prime \prime} \mathrm{W}$ & 128 & 39 \\
\hline 16 & Sluggan bog & $54^{\circ} 48^{\prime} 45.89^{\prime \prime} \mathrm{N}$ & $06^{\circ} 17^{\prime} 28.58^{\prime \prime} \mathrm{W}$ & 114 & 35 \\
\hline 17 & Owenduff bog & $53^{\circ} 57^{\prime} 56.41^{\prime \prime N}$ & $09^{\circ} 46^{\prime} 27.82^{\prime \prime} \mathrm{W}$ & 52 & 16 \\
\hline \multirow[t]{2}{*}{18} & Clara bog & $53^{\circ} 19^{\prime} 38.28^{\prime \prime} \mathrm{N}$ & $07^{\circ} 37^{\prime} 29.86^{\prime \prime} \mathrm{W}$ & 176 & 54 \\
\hline & ARGENTINA & & & & \\
\hline 19 & Puerto Moat bog & $54^{\circ} 57^{\prime} 45.20^{\prime \prime} \mathrm{S}$ & $66^{\circ} 44^{\prime} 25.07^{\prime \prime} \mathrm{W}$ & 88 & 27 \\
\hline 20 & Harberton bog & 5452’05.12”S & $67^{\circ} 18^{\prime} 01.01^{\prime \prime} \mathrm{W}$ & 44 & 13 \\
\hline 21 & Tierra Australis bog & $54^{\circ} 36^{\prime} 16.20^{\prime \prime} \mathrm{S}$ & $67^{\circ} 45^{\prime} 50.05^{\prime} \mathrm{W}$ & 383 & 117 \\
\hline
\end{tabular}

\section{Methods}

The peat samples are subjected to two lines of analysis:

A/ a study of particulate matter by using light and scanning electron (SEM) microscopes $\mathrm{B} /$ geochemical analyses of peat ash and soil using ICP-MS.

To date more than 3000 samples have been analysed this way. The temporal resolution of the sampling, established by ${ }^{14} \mathrm{C}$ dating, is approximately 50 years $\left(1 \mathrm{mmYr}^{-1}\right)$ (e.g. Franzén 2002).

Sampling

Samples from the different mires were taken with a $50 \mathrm{~mm}$ diameter Byelorussian peat corer. Sampling was always performed in the highest central parts of the peatland to get the longest record possible. As mentioned above bogs start to develop in a moist depression expanding laterally as they thicken. Samples were cut out in $5 \mathrm{~cm}$ levels (allowing for a temporal resolution of c.50 years assuming a peat accumulation rate $\mathrm{c} .1 \mathrm{~mm}$ per annum). Two separate 
cores (A and B), situated less than $25 \mathrm{~cm}$ from each other were taken from each bog. The Asample is used for the particle studies, the B-sample for the geochemical investigations. To avoid contamination and oxidation the samples are immediately placed in zipper bags, which are kept cool before lab preparation. Since the peat turn from anoxia to oxic conditions when exposed to air, the preparation work is made as soon as possible after sampling to avoid acid digestion of some particles.

\section{Dating}

For this project, more than 100 calibrated (Stuiver and Reimer 1993) AMS ${ }^{14} \mathrm{C}$-datings have been made, in vertical profiles. In addition, tephrochronolgy has been used (e.g. Pilcher and Hall, 1992), as well as geochemical signal levels such as for the element lead (Renberg et al. 2000, 2001). Individual tephra horizons have been identified by the use of SEM-EDX. Another less reliable dating method used is the method of constant bulk density. This method is based on the assumption that the peat in one specific level within a mire has the same bulk density and that a peatland has grown at the same rate over the whole surface, since peat growth started (Lode et al., 2001, Lode, 2002). The method could also be applied between different mires within a restricted region assuming that the peatland development within that region has been similar. This method gives no information on the exact timing but is more a short-cut to get an idea of the approximate time of formation of a certain stratigraphical level, and enables you to find e.g. tephra horizons more rapidly. All dates and ages in the following text are given in calibrated years BP.

\section{Laboratory analyses}

The laboratory work followed two different preparation lines.

The A-samples were soaked in a strong $\mathrm{NaOH}$ solution for 24 hours. Subsequently, a long sieving, decantation and washing process resulted in a small quantity of mineral grains and fragments of charcoal. The mineral samples were placed under lid in $60 \mathrm{~mm}$ glass Petri dishes and the material in the Petri dishes was first scanned under a polarizing microscope to record the frequency of volcanic glass shards and phytoliths. The samples were then scanned more intensively, $\mathrm{mm}^{2}$-wise under a light stereomicroscope using a blue grid-patterned underlay. The total numbers of spherules and micro-meteorites in each sample were recorded. A strong neodymium magnet was moved under the Petri dish to identify and count other magnetic particles. All spherules and micro-meteorites were marked out with a small red dot for easier access in the future. Particles for analysis and those of special interest were picked out with a thin insect needle and placed on SEM aluminium stubs, using double sided carbon tape to keep them in place. These particles were studied in detail and analysed with a Scanning Electron Microscope (SEM-EDX). Images were taken, stored, and processed digitally.

A small portion of each dried $\mathbf{B}$-sample was kept for possible ${ }^{14} \mathrm{C}$-datings and the remainder was combusted at $550^{\circ} \mathrm{C}$. Ash content was calculated as the residual over the dry weight. The peat ashes were dissolved in a 50\% Aqua Regis solution and stored in $50 \mathrm{ml}$ polypropylene bottles. The initial digestion was made in an oven at $50^{\circ} \mathrm{C}$ over 12 hours. Diluted solutions $(5 \%)$ were analysed with the ICP-MS and the concentrations of 68 major and trace elements were measured using two multi element standards (Merck Standard VI CertiPur Lot No. OC476565 and Agilent Standard 4 Lot No. 20-170AS). With this background information, an 
attempt was made to evaluate both the main sources and the temporal variations in input fluxes of mineral matter and associated elements to the bogs over the whole of the Holocene (i.e. the last c. 10,000 years).

\section{Results and discussion}

Three different records of cosmic phenomena have been identified in the peat samples. Two types of particles: (i) irregular micrometeorites and (ii) magnetic and nonmagnetic spherules have been observed; and in addition an altered geochemical signature has been detected at certain levels in the stratigraphy.

\section{Particles}

The particulate study has revealed the occurrence of microscopic glass and iron spherules, which are concentrated in layers consistent with specific time intervals (Franzén 2006). I believe that these microscopic spherules are likely of cosmic origin i.e. they are formed by ablation of extra terrestrial particles during their atmospheric entrance. During the systematic scanning of the peat samples several thousand spherules have been recorded. The dominant fraction (c. 90\%) of these are black magnetic spherules made up of pure magnetite. The remainder of the spheres are glassy types, exhibiting great variety in size, appearance and chemical composition. Most of these are transparent with a yellow to brown tone but others are colourless clear. One of the most spectacular spherules was found in one of the Swedish bogs. The spherule itself is made of glass but it appears to have been impacted by a smaller iron sphere during atmospheric flight (Fig.6).

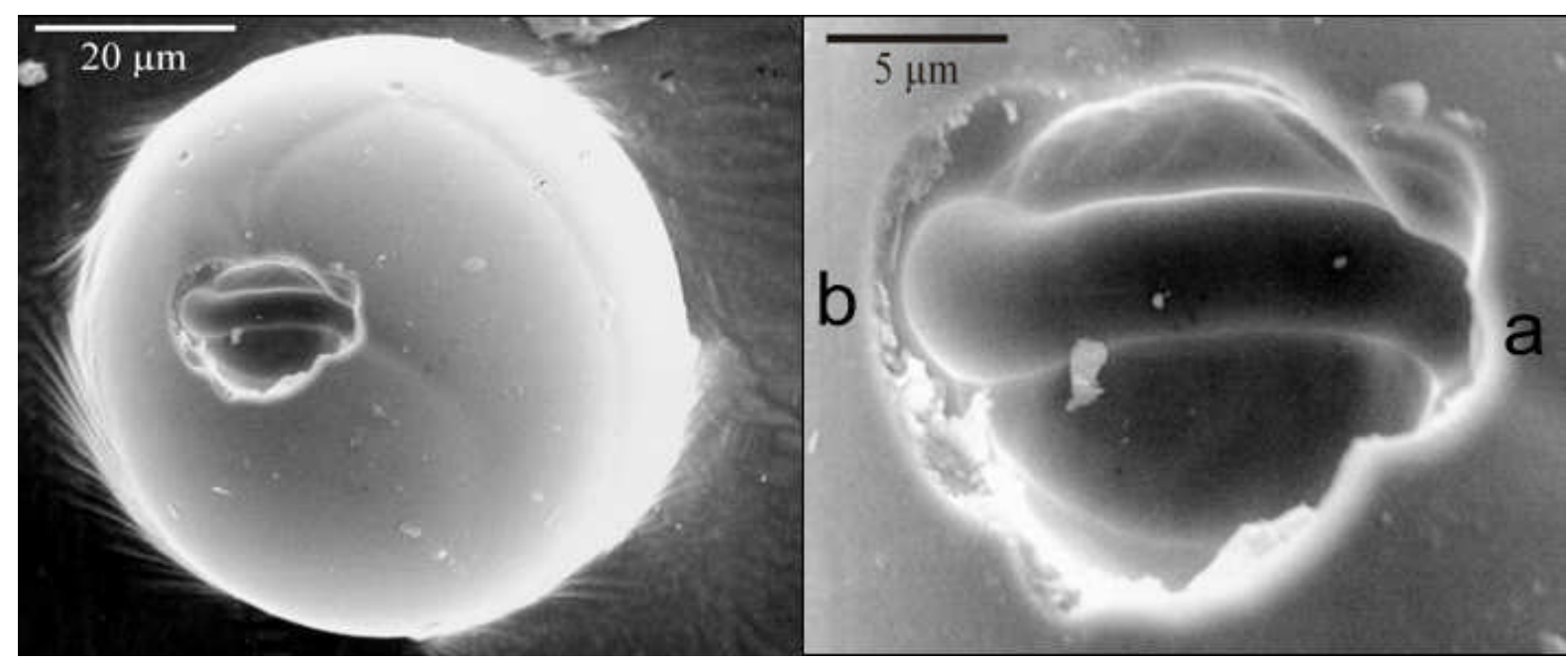

Fig. 6. Transparent brownish green glass spherule from Lyngmossen bog (Table 1, \# 7) c. 1450 BP. The crater formed is probably an impact structure. The interior of the crater as well as the bright crater rim, have a very high iron content compared to the spherule itself. The right hand image is a close-up image of the crater. The spherule was most likely hit by a much smaller (c.1 micron), fast rotating iron spherule, which entered at the right side (a) and went out at the left (b). Note the halved outlet crater to the left. The large crater itself was probably formed by a gaseous explosion.

Extraterrestrial dust particles have been recovered from various terrestrial environments, most notably deep-sea sediments (Brownlee, 1981). These rare occurrences have established the 
presence in terrestrial sediments of an extraterrestrial component that originated either as micrometeorites or products of the ablation and/or explosion of meteorites as they pass through the atmosphere (Hagen et al. 1990, Zbik and Gostin 1995). In the case of iron meteorites the surface-heating boils droplets of molten metal into the surrounding air. Instantly cooled and solidified, these droplets form microscopic spherules that settle to the earth along with the remains of the core meteorite. In the case of stony meteorites the ablation products may end up with particles more or less enriched in iron. Iron has the highest boiling temperature of the main elements, and would last longest during the atmospheric entrance. The stony meteorite spherules are glassy, and are transparent with yellow or brownish nuances to opaque and black. The gassed-off elements from both iron and stony meteorites turn up sooner or later at the surface of the earth, caught by the Earth's gravity. Both iron and stony meteorites appear with a fusion crust that is normally enriched in iron.

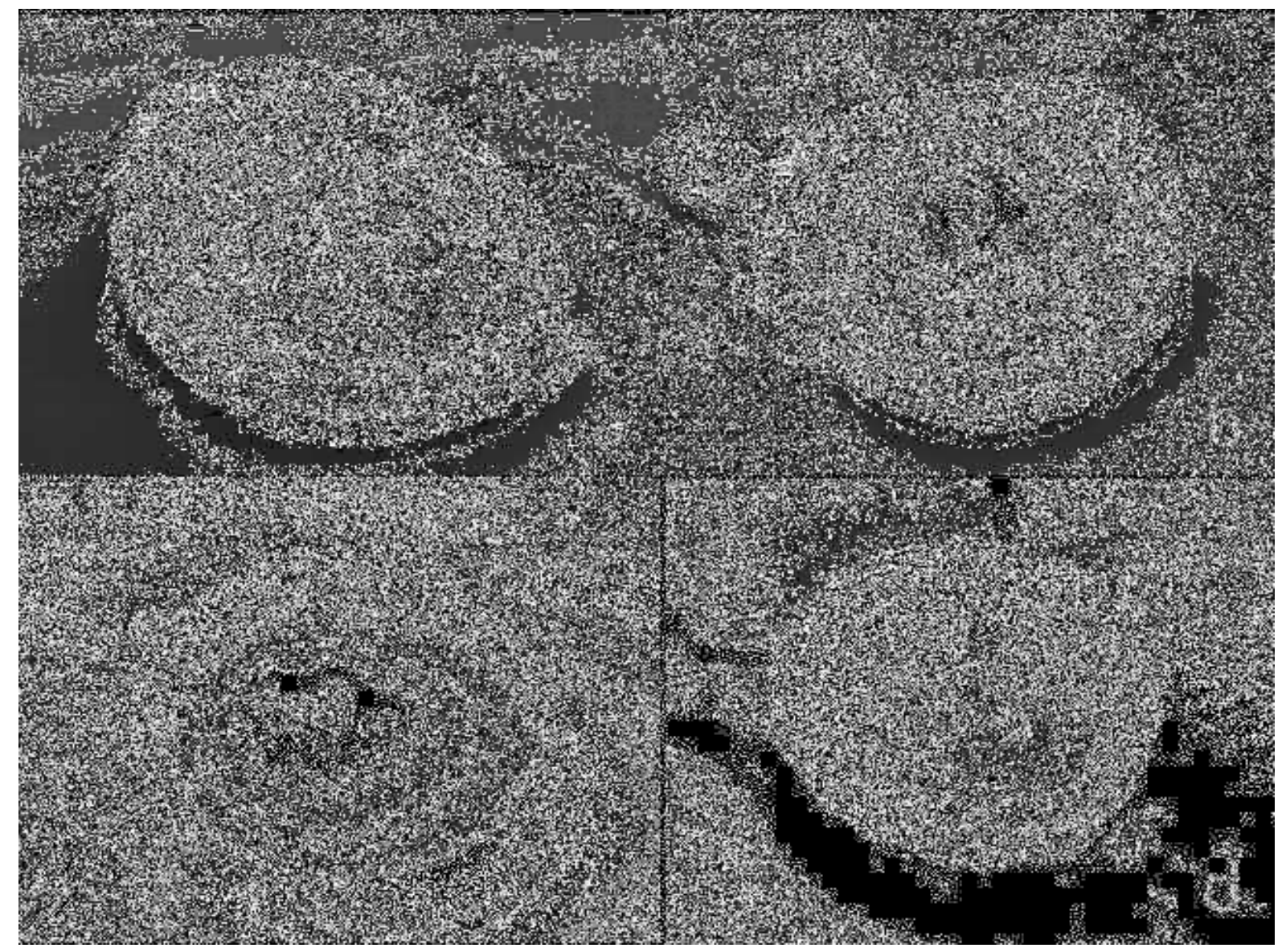

Fig. 7. Various micrometeorites; (a) - Lyngmossen, SW Sweden (Table 1, \#7), c. 750 BP, (b) - Harberton bog, Tierra del Fuego, S. Argentina (Table 1, \#20) c. 450 BP, (c) - Harberton bog, Tierra del Fuego, S. Argentina, c. 700 BP, (d) - Moat bog, Tierra del Fuego, S. Argentina (Table 1, \#19), c. 700 BP.

The annual influx of cosmic material has been calculated at between $1.6-2.0 \times 10^{9} \mathrm{~g} \mathrm{yr}^{-1}$ to $1.5 \times 10^{11} \mathrm{~g} \mathrm{yr}^{-1}$ (d'Almeida et al. 1991, Kane and Chester 1993, Ceplecha 1996). Distributed over the whole area of the world this means c. 0.03 to $0.3 \times 10^{-3} \mathrm{~g} \mathrm{~m}^{-2} \mathrm{yr}^{-1}$ or about the magnitude $10^{-5}$ to $10^{-3}$ of the preindustrial ash content in ombrotrophic peats measured in this study. An additional feature associated with extraterrestrial activity are the micro-tektites that are formed from terrestrial or cosmic material by the energy released during a larger meteorite impact on Earth's surface. The likelihood of finding such particles in Holocene peats is small. In addition to the many reports from the Siberian Tunguska event of 1908 the 
only other report on findings of impact ejecta (allocthonous minerals and iridium), is a relative recent study of the Kaali impact crater of Estonia dating back at c. 800-400 B.C. (Veski et al. 2001).

Proper micrometeorites are extremely rare in the peat samples; throughout the more than 3000 samples studied here, only a few tens have been interpreted as such. Under the light microscope they appear as dull, grey to black, and they are normally detected only by their magnetic properties. In the electron microscope their fusion crust surface gives a smooth "melted" impression as if the sharp edges of a crushed mineral grain had been melted off. The surface is often patterned with deep cavities or distinct micro-regmaglyptic structures. Figures 7 a-d show four possible micrometeorites found in peat from Harberton bog, Tierra del Fuego, Argentina.

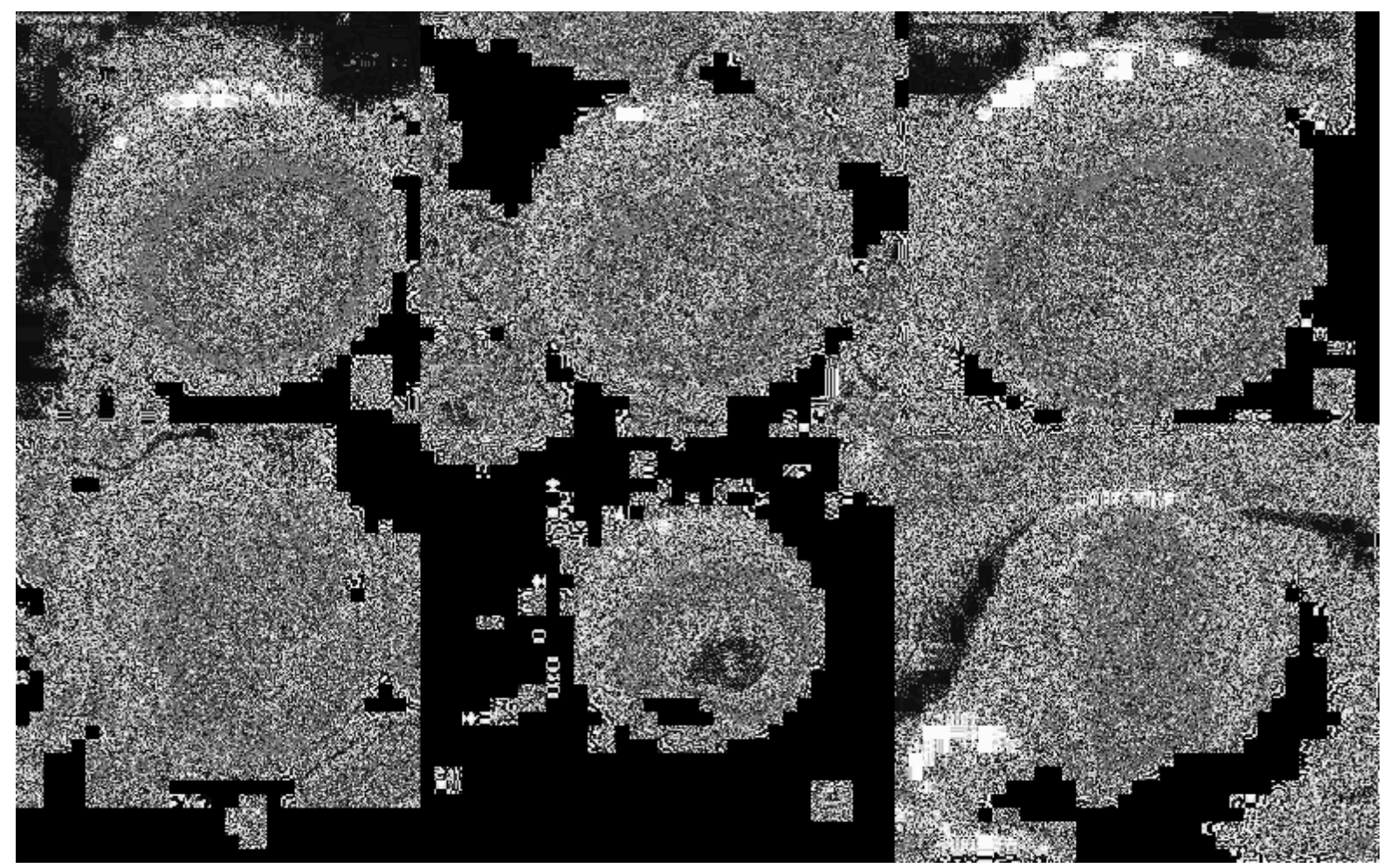

Figure 8. Various magnetite spherules; (a) - black magnetic spherule with smooth surface. Appears as very glossy under the light microscope [Dömle mosse, Sweden, Table 1, \#1] c. 4300 BP), (b) - black magnetic spherule with well developed dendritic surface structures. Small round objects are glossy magnetite spherules [Clara bog, central Ireland (Table1, \#18), c.400 BP], (c) - black magnetic spherule with polygon plate surface structures ("Soccer ball pattern") [Harberton bog, Tierra del Fuego, S. Argentina (Table 1, \#20), c. 450 BP], (d) black magnetic spherule with a yarn-ball-like dendritic surface structure. The spherule appears to be hollow with some round entrance cavities [Gällseredsmossen bog, SW Sweden (Table 1, \#11), c. 400 BP], (e) - black magnetic spherule. Appears to be hollow with a big hole. Weakly developed dendritic surface structures [Harberton bog, Tierra del Fuego, S. Argentina, c. 1450 BP], (f) - crushed black magnetic spherule. The hollow interior exposes a well developed dendritic surface structures [Sluggan bog, N. Ireland (Table 1,\#16), c. 400 BP].

Spherules are much more common and occurred in almost all peat samples studied, but they are more abundant in some levels than others. They are easily detected by their spherical shape and the mainly shining glossy appearance. The origin of such spherules has been a matter of lively debate since they were first described from deep-sea deposits (Murray and Renard 1891, Pettersson and Fredriksson 1958). During the decade following Pettersson's and Fredrikssons's (1958) study numerous reports were published on spherules from a large variety of different environments. Whereas some research claims them to be mainly of cosmic 
origin, others claim them to be mainly natural terrestrial objects or contaminations of anthropogenic origin. It soon became obvious that it was almost impossible to distinguish between natural spherules and spherules formed by different human activities. The modern world is full of such spherules and they are produced as the result of a large variety of different human activities including: (1) iron spherules made by welding or metal cutting, (2) insulation material such as glass and stone wool, (3) furnace insulation bricks, (4) atomic explosions, (5) industrial spherules e.g. from steel works or combustion of solid fuels and (6) traffic pavement paint, all of which might be introduced one way or the other as contaminants during all research procedures, from sample collection to final analysis.

Various methods have been tried in the struggle to sort out e.g. cosmic iron spherules from industrial, for instance by the presence of wüstite (e.g. Taylor et al. 1996), a form of magnetite which is believed to form in the upper atmosphere under low oxygen pressures. The natural terrestrial spherules are believed to originate either from volcanism, forest wildfires or lightning.

Whereas spherules in marine deposits have been reported frequently over the years, the occurrence in peat is much less reported and only a few studies have been made e.g. in Estonia (Raukas 1997, Raukas et al. 2001) and in the Tunguska region of Siberia (Dolgov et al. 1971, Vasilyev et al. 1971, Nazarov et al. 1983, Kolesnikov et al. 1998). The microspherules found in peat stratigraphies are of two kinds: (1) shiny metallic grey or black magnetic spherules and (2) transparent or opaque nonmagnetic spherules.

The black magnetic spherules normally appear very glossy under the light microscope, and are easily distinguished from other round objects by this property. Some magnetic spherules, however, are dull. In the SEM the cause of difference is revealed; whereas the glossy spherules have a smooth surface (Fig.8a) the dull have a rough surface. The degree of dullness is generally ruled by the quantity of dendritic (Fig.8b) or polygon plate (Fig.8c) structures that have developed on their surfaces. These surface structures are likely formed by a super cooling condition of the fluid during the solidification process. This process, which begins from the outer shell of a fluid metallic drop, may also explain the occurrence of cavities (Fig.8d), and holes (Fig.8e) inside the spherules (Carusi et al. 1972). The dendritic structures may also be found on the inner walls of these cavities (Fig.8f). SEM-EDX analyses made here show that the vast majority of these magnetic spherules are made of pure magnetite.

The nonmagnetic spherules are less frequent than the magnetic ones, and the relative share does not exceed 5-10 per cent of the total number of spherules. These glassy spherules have a wide range of colours and transparencies spanning from e.g. opaque and black to smoky and grey, brownish to even colourless transparent. The colour generally reflects the content of iron; the more iron the darker the spherule (Franzén, 2006). Many of the glassy spherules have closed vesicles, visible in the light microscope, but not in the SEM. Whereas most of these spherules are perfectly polished pearl-like objects (Fig. 9a) some of them are covered with small depressions, giving them a golf ball-like appearance. Others are perforated with deep holes and cavities (Fig.9 b,c). Whereas many of these surface structures are weathering phenomena (Fig. 9e), others are likely formed during the solidification processes (Fig. 9d). Some have their surfaces cracked by rapid cooling (Fig.9f). In rare cases, impact structures such as craters (Fig. 6), shock wave rings or frozen splash-up cascades, bare witness of collisions with smaller objects during the atmospheric flight.

The size of the spherules found in the peat stratigraphies varies from less than 1 micron to a maximum of c.100 microns, whereas the spherules reported from deep sea sediments and the Antarctic ice cap are rather large, with sizes ranging from 0.1 to $1 \mathrm{~mm}$. Spherules smaller 
than $1 \mu$ are impossible to detect with the magnification available in the light microscope. SEM scanning of complete samples, however, confirms the lack of particles smaller than 1 micron. This lack is probably due to loss as a result of the restricted sedimentation time used in the decantation procedures described above. The mean size of the spherules measured in the SEM is c. 6 microns.

Single stray spherules have been found in most samples investigated, however, the large concentrations of spherules are only found in rather distinct layers. These layers never coincide with volcanic horizons, nor with high frequencies of charcoal and tar, ruling out both volcanic and wildfire origin for these spherules. However, comparison of the ICP-MS measurements with the spherule distribution revealed that a high concentration of spherules coincide with the cosmic geochemical signatures described below.

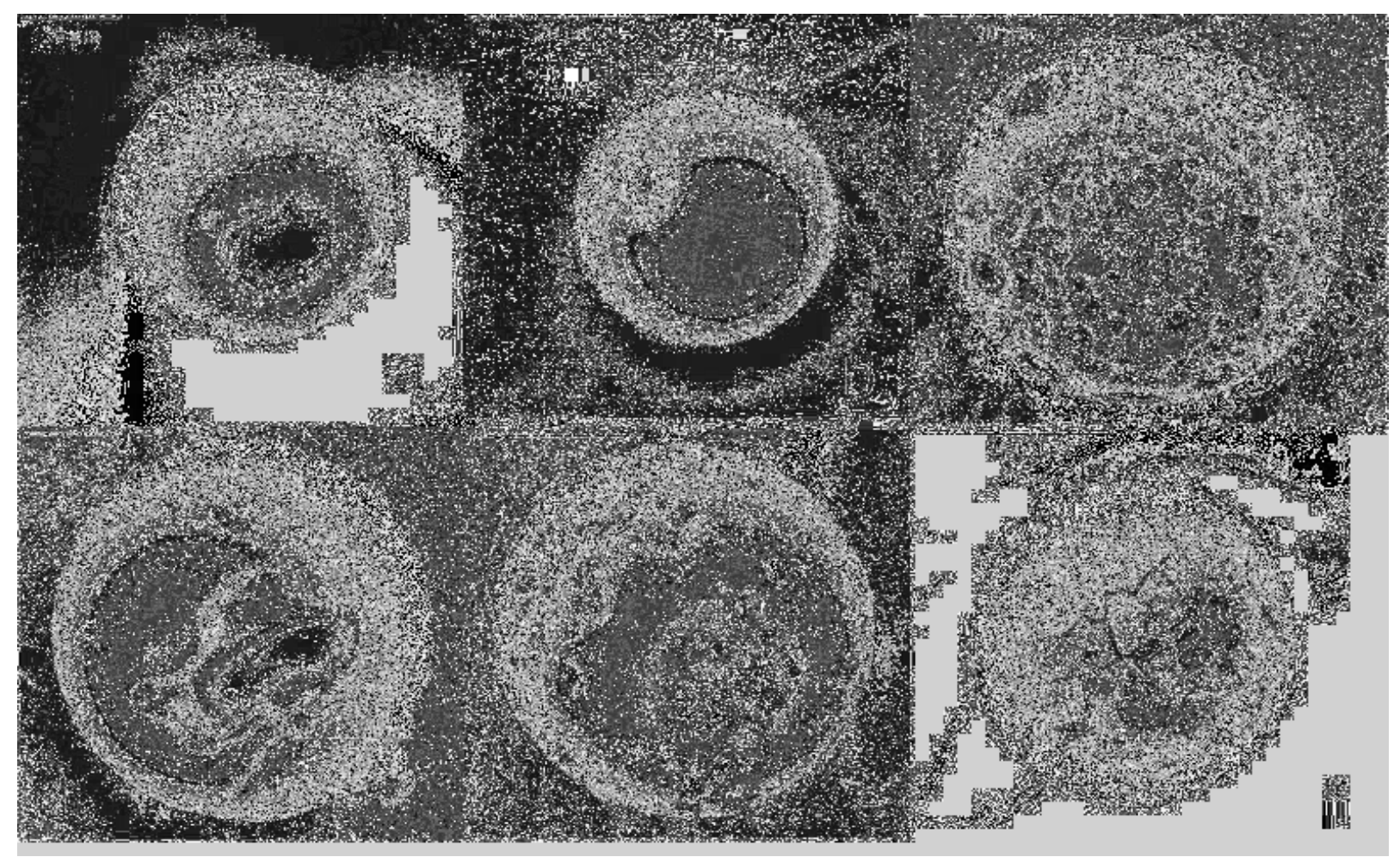

Fig. 9. Various glass spherules. (a) - dark brown glass spherule. [Harberton bog, Tierra del Fuego, S. Argentina, (Table 1, \#20) c. 1450 BP], (b) - brownish transparent glass spherule [Fallahogy bog, N. Ireland, (Table 1, \#15) c. 650 BP], (c) - colourless transparent spherule patterned with small cavities [Dömle mosse bog, Sweden, Table 1, \#1) c. $3700 \mathrm{BP}$, (d) - colourless transparent glass spherule with a deep cavity which was probably form during solidification. Smaller attached spherules have the same composition as the main spherule [Sluggan bog, N. Ireland, Table 1, \#16, c. 750 BP], (e) - brownish green transparent glass spherule with weathering pits. The small cavities could also have been formed by microbiological digestion [Sluggan bog, N. Ireland, c. 750 BP], (f) - yellowish transparent spherule. The cracked-up surface structure was probably caused by rapid cooling [Harberton bog, Tierra del Fuego, S. Argentina, (Table 1, \#20) c. 1450 BP]. 


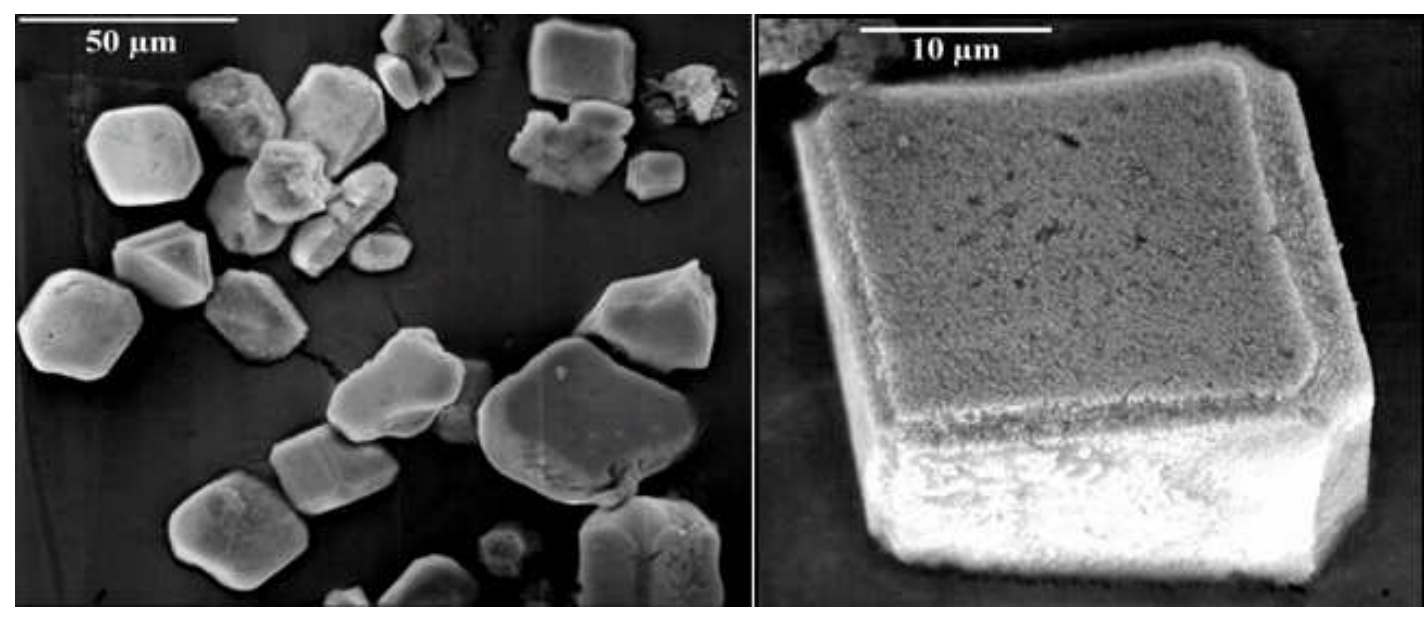

Fig. 10. Calcite crystals found in bog peat. The crystals have a typical rhombic form. (Hjortemossen bog, S. Sweden, Table 1, \# 2).

Most of the soluble substances deposited on a bog surface are drained out of the system with horizontal sub-surface runoff; however some, such as calcium, is fixed in the catotelm (the lower anoxic part of the peat stratigraphy). Calcium, which is the major element in most peat ashes (e.g. Fredriksson 1996) (Franzén 2006, Table 11.1), can form rhombic carbonate crystals. The main supply of calcium comes from marine aerosols (e.g. Franzén 1990), that can be deposited dry or dissolved in the waters of rain and snow. The formation mechanisms of such calcite crystals are still not fully understood, but they are never found in the upper oxygen-rich zone, only in the anaerobic catotelm. Similar authigenic calcite rhombs are found in the anoxic parts of marine sediments, formed on the substratum of deposited foraminifers (Pederstad and Aagaard 1985), on calcite spherulites (Verrecchia et al. 1995) or cementing organic-rich sediments (Irwin et al. 1977), but to my knowledge they have never been described from peats before. The extraction of these crystals is a delicate matter. Whenever a peat sample is taken out of its anaerobic environment and is exposed to the air, the crystals are rapidly dissolved in the acid peat water. The preservation of the crystals shown in Figure 10 a,b was made by adding a weak $\mathrm{NaOH}$ solution to the peat sample in the field, immediately after sampling.

\section{Geochemistry}

The amount of material deposited on the surface of raised bogs is extremely low compared to other sedimentary records. The average raised bog peat sample contains about 0.5 to 1.5 per cent dry weight. If we use a pore space value of 50 per cent, a mean density of 2.65 and the peat deposition rates given by the various sources of dating, the amount of natural dust, including the authigenic minerals such as phytoliths (see. e.g. Franzén 2006), as calculated from the peat ash contents in southern Sweden and Ireland bogs, is estimated at about 0.05$0.1 \mathrm{~mm}$ per 1000 years in pre-industrial times. This is about 10 to 100 times lower than the deposition rate of the slowest accumulating red clays of the sea floor (Seibold and Berger 1982).

The geochemical study has shown that the strata where spherules are common also host the signature of cosmic material. For this study I have not chosen to measure iridium or any other element of the platinum group as for the large number of peat analyses made the pre-treatment to detect iridium would have been too time-consuming. The main two parameters that have been studied instead are 1/ the lanthanide group of element formation after chondrite 
normalization (Cornell 1993) and 2/ the internal relationship between the three elements of titanium (Ti), vanadium (V) and cobalt (Co). These two parameters, which are easily achieved with simple acid digestion and ICP-MS analysis, provide two independent cosmic indices that show the degree of cosmic contribution to the deposited sediments.

\section{The lanthanide index}

The lanthanides, or Rare Earth Elements (REE), are the elements including scandium (Sc), yttrium (Y), and the periodic row of lanthanides ranging from atomic numbers 57-71. No other group of elements investigated here has a more constant mutual relationship than the lanthanides. The lanthanides are very resistive and only two rare earth elements can form different ions in nature: $\mathrm{Ce}^{4+}$ and $\mathrm{Eu}^{2+}$ (Cornell 1993). The lanthanides are about 300 times more common in terrestrial material than in cosmic dust, and a factor $10^{3}$ to $10^{4}$ more common in cosmic dust than in sea water; hence they can be used to evaluate the relative degrees of terrestric, marine and cosmic influences in peat deposits.

Lanthanides' relative abundance; 1 (terr.) : $\sim \mathbf{3 \times 1 0 ^ { - 2 }}(\mathbf{c o s m}):. \sim \mathbf{1 0}^{-6}($ sea $)$

The transition from minerotrophy into ombrotrophy in bog profiles developed from fens, carrs and swamps is clearly defined by the lanthanides' signal (Franzén 2006). Figure 11 shows the distribution of lanthanum (La) in the profile from Gällseredsmossen bog, situated some $40 \mathrm{~km}$ inland from the west coast of Sweden (Table 1, \#11), where the transition from minerotrophy to ombrotrophy at a depth of around $500 \mathrm{~cm}$ is clearly visible, with a factor $3 \times 10^{3}$ decrease of La. Bogs which were formed directly on the mineral soil as a result of paludification normally lack this and have an overall low REE concentration. The sharp decrease of lanthanides going from the lower minerotrophic (fen) peats to the upper ombrotrophic (raised bog) peats indicates that atmospheric deposition to raised bogs is very little affected by terrestrial mineral sources but rather by marine or/and cosmic. The top layers of all investigated bogs also show a slight increase in the REE signal due to modern deposition of dust resulting from different human activities over the last 50-100 years. The distinct decrease of the lanthanides in the transition from minerotrophy to ombrotrophy; that is, from fen to bog, was found in all peat stratigraphies with this developmental history. Hence the lanthanide curve can be used as a tool, more precise than the traditionally used, but not equally distinct decrease in ash content to distinguish this transition (Franzén 2006). This fact was used here to distinguish minerotrophic peats from ombrotrophic in order to separate peat samples with a mixed supply of nutrients from those with a pure addition of atmospheric constituents only. 


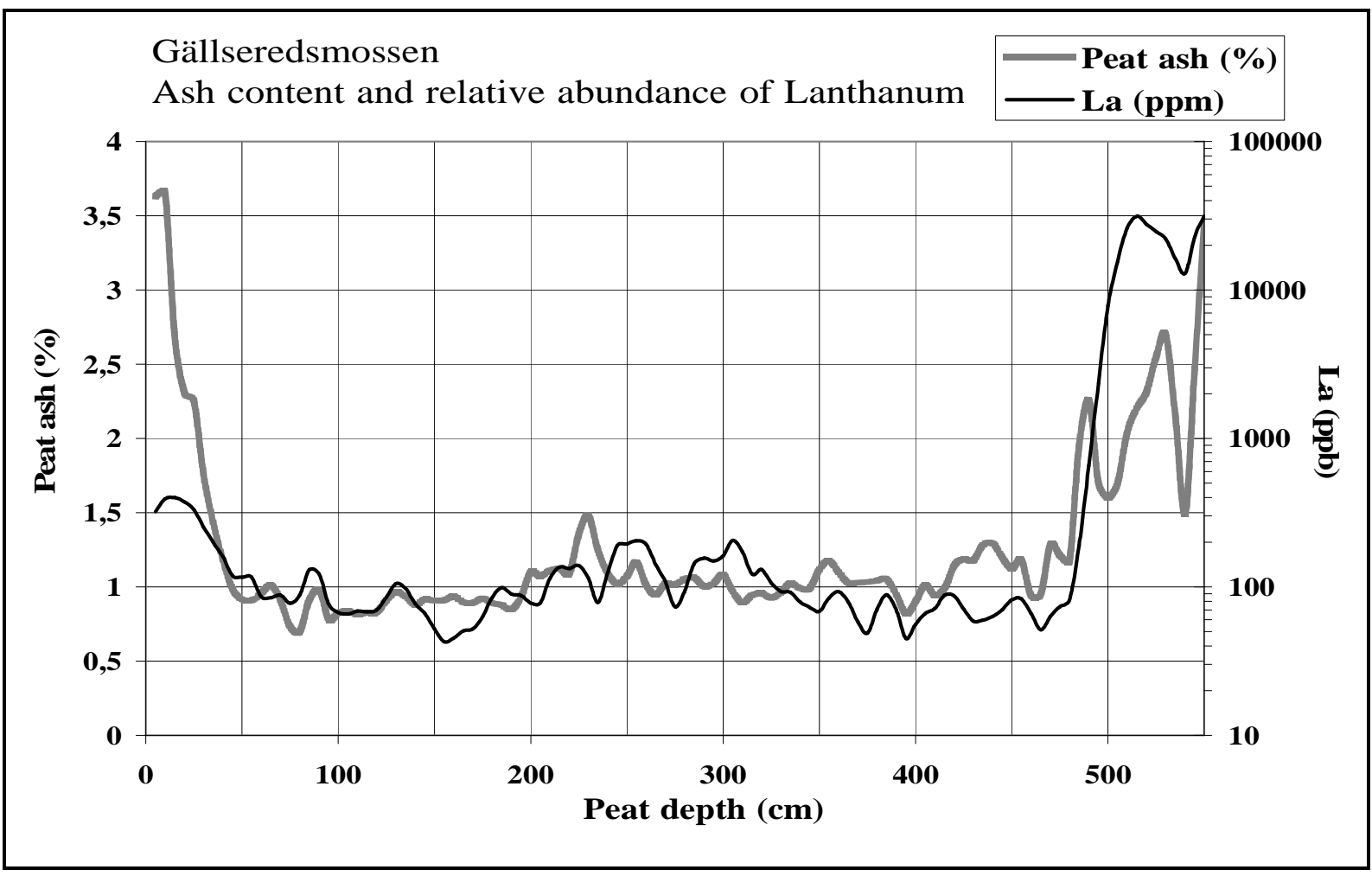

Fig. 11. Stratigraphical distribution of peat ash (\%) and lanthanum in peat (La ppb) in the Gällseredsmossen bog, S. Sweden (Table 1, \#11). Note logarithmic scale of scale for La.

Since the terrestrial influence is obviously very low in true ombrotrophic peat and the fact that lanthanides are so extremely rare in the marine component, the lanthanides can also be used to investigate the influx of cosmic material by looking at the relative concentration of the REE elements (Boynton 1984). Bulk extraterrestrial concentrations of REE, normalized by dividing them by the concentrations in a reference chondrite sample, plot in quasi-horizontal line (Cornell 1993). In terrestrial (continental crust) material, in contrast, the lighter REE's are relatively more common than the heavier ones. Additionally, plagioclase has a strong affinity for the reduced form $\mathrm{Eu}^{2+,}$ depleting it in liquid magmas from which it crystallizes, leading to depletion in the residual fluids and in later precipitated mineral. Thus, continental rocks are generally characterized by europium depletion (McLennan and Taylor 1981, Cornell 1993) and is less abundant than the neighboring samarium ( $\mathrm{Sm}$ ) and gadolinium (Gd) (Fig. 12b). Hence a similar plot line for terrestrial REE's will slope down from lighter to heavier REE's (Fig.12a) and Eu will be relatively depleted. 


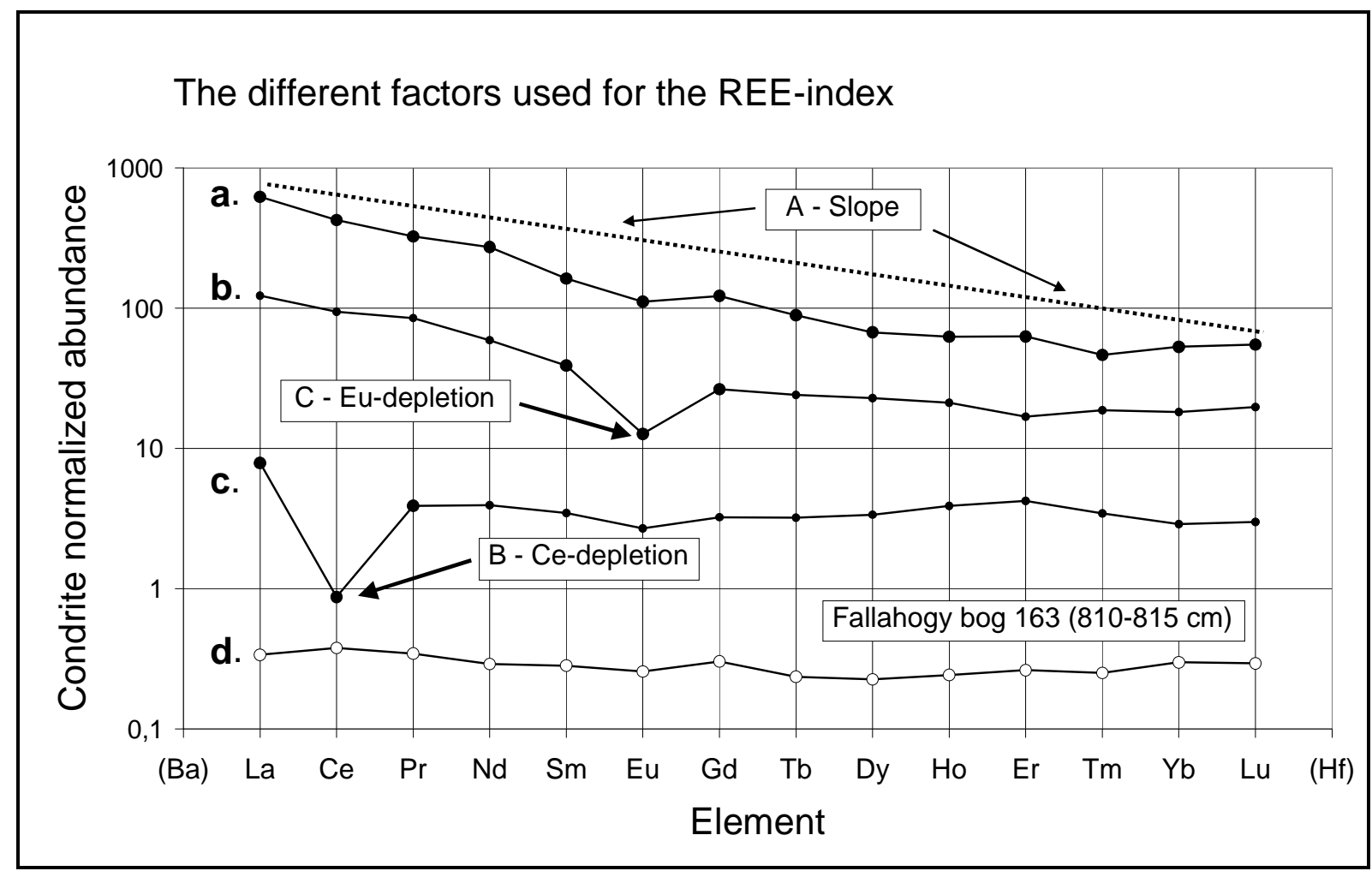

Fig. 12. The different factors used to calculate the REE index. The top graph (a) graph shows the chondrite normalised abundance of REE's in a typical minerotrophic (fen) peat sample whereas the lower graph (d) is an ombrotrophic (bog) peat sample giving a high REE index.

Seawater, however, is typically depleted in cerium $(\mathrm{Ce})$ by comparison with neighboring lanthanum (La) and praseodymium (Pr) due to oxidation of $\mathrm{Ce}(\mathrm{III})$ to insoluble $\mathrm{Ce}$ (IV) (e.g. De Baar et al. 1985, Alibo and Nozaki 1999). Hence a dominant marine influence in peat could easily be detected by cerium depletion (Fig.12c). The horizontal graph for sample 163 from Fallahogy bog of Northern Ireland, for instance, (Table 1, \#18), with no distinct Ce or Eu depletion, indicates that cosmic dust influx strongly dominated over the marine and terrestrial sources (Fig. 12d). The sample presented in Figure 12d is only one of a row of 6 samples or $30 \mathrm{~cm}$ of peat in that stratigraphy sequence, with a similar horizontal distribution of chondrite normalized lanthanides. With the peat growth rate calculated from the ${ }^{14} \mathrm{C}$ datings this means that cosmic material influx dominated over a period of $\sim 400$ years between c. 8200 and 8600 cal yrs BP.

These three properties of the lanthanide group, that is, their terrestrial vis-à-vis their extraterrestrial/marine appearance can be utilized to establish the relative concentration of cosmic versus earthly derived particles in peat ash. The lanthanide index used here is based on the three different factors: (A) the internal relationship (slope) between heavy and light REE's, (B) cerium $(\mathrm{Ce})$ depletion and $(\mathbf{C})$ europium $(\mathrm{Eu})$ depletion, that are quantified using the coefficients of variation of three groups of the lanthanides:

REE Index $=\mathbf{A} \times \mathbf{B}^{2} \times \mathbf{C}($ range 0 to $\leq 1)$

where: 


$$
A=1-\frac{\sum_{i=1}^{17}\left|x_{i}-\bar{x}\right|}{\sum_{i=1}^{17} x_{i}},
$$

where $x=\{S c, Y, L a, C e, P r, N d, P m, S m, E u, G d, T b, D y, H o, E r, T m, Y b, L u\}$,

$$
B=1-\frac{\sum_{j=1}^{3}\left|y_{i}-\bar{y}\right|}{\sum_{j=1}^{3} y_{i}},
$$

where $y=\{L a, C e, P r\}$, and

where $z=\{S m, E u, G d\}$.

$$
C=1-\frac{\sum_{k=1}^{3}\left|z_{i}-\bar{z}\right|}{\sum_{k=1}^{3} z_{i}},
$$

High values of the REE index (REE Index near one) indicate a predominance of cosmicorigin material in the sample, whereas values near zero indicate a predominance of terrestrialor marine-origin material.

The index varies widely within the population of peat samples. Whereas the lower minerotrophic peats have indexes which lie in the range of 0 to $\leq 0.05$ the upper ombrotrophic parts range from 0.05 to $\geq 0.75$. The highest values are only found in the ombrotrophic bottom parts in the mires of Ireland (Fallahogy and Clara bogs) and Tierra del Fuego (Harberton and Moat bogs) where the oldest layers of in Harberton bog reaches back as far as 14000 years BP. Even if the raised bogs of S. Sweden have bottom layers dating back 9-10 000 years or more, they generally have an ombrotrophic history of less than 5-6000 years i.e. the transition from fen to bog seems to have occurred around 5-6000 years BP. The development of REE index over time, in a combined graph for 14 Swedish, four Irish and three Fuegan bogs with an ombrotrophic history is shown in Figures $14 \mathrm{a}$ and b. Figure 14a shows the whole development from the oldest peat layers dated (Harberton bog) till present whereas Figure $14 \mathrm{~b}$ covers the development from $7000 \mathrm{BP}$ onwards.

\section{The cobalt index}

The cobalt index is basically the length (a non dimensional unit) of the cobalt vector in a TiVCo triplot procedure ( $\mathrm{Ti} \times 1, \mathrm{~V} \times 10$ and $\mathrm{Co} \times 100$ ). Titanium was chosen because it is relatively enriched in terrestrial deposits, vanadium because it has a high relative share in seawater and cobalt because it's rare in both terrestrial and marine environments but very common in extraterrestrial material. The cobalt index of terrestrial material and minerotrophic peats normally lies in the range of $\leq 20$ whereas the ombrotrophic peats have values of c. 20 110. Like with the REE index the highest Co indexes are found in the lowest ombrotrophic sections of the mires. A plot showing REE index versus Co-index of all ombrotrophic peat samples are shown in Figure 13. The development of the cobalt index over the Holocene period is shown in Figures $14 \mathrm{a}$ and $\mathrm{b}$. 


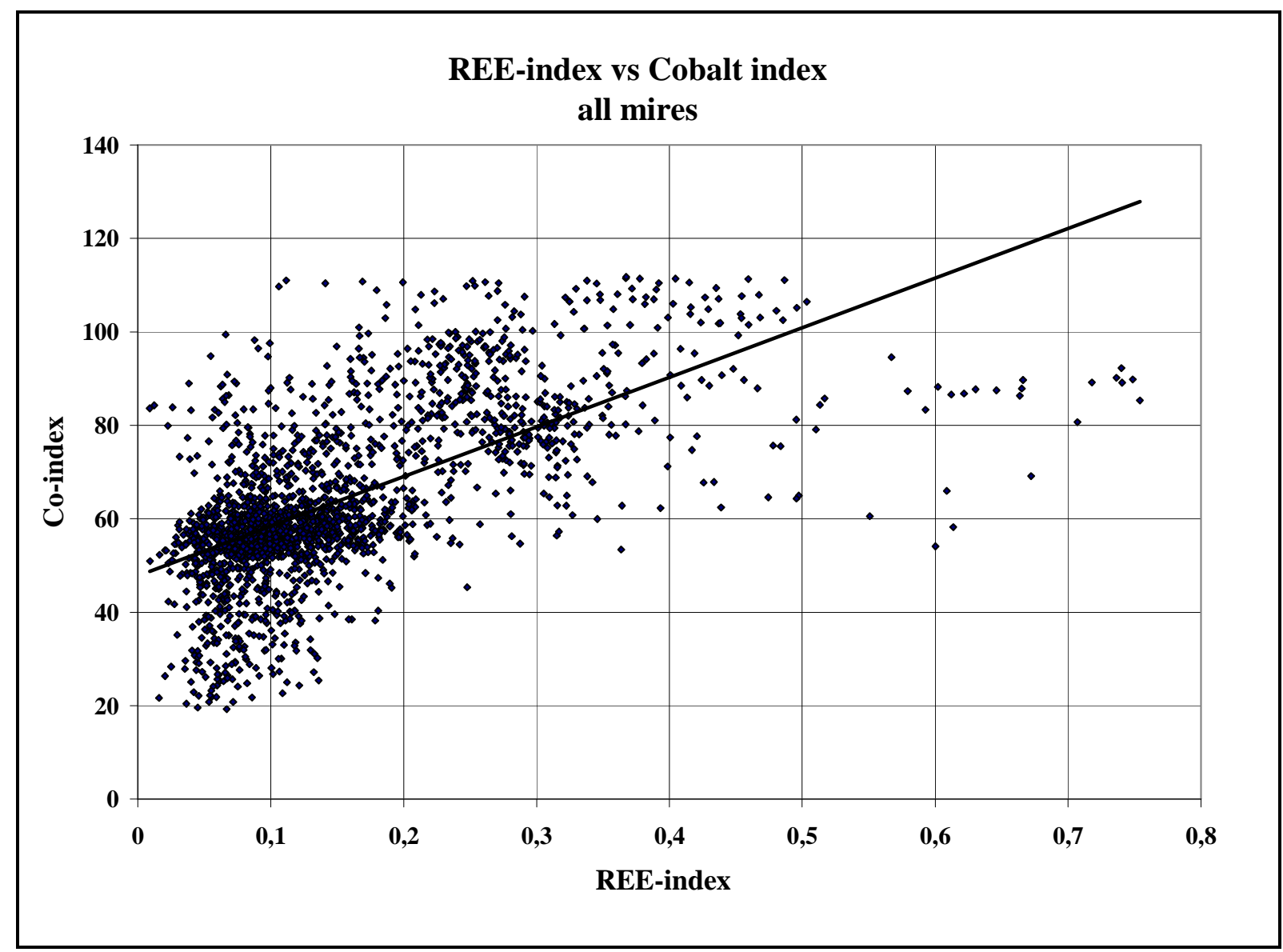

Figure 13. Cobalt index plotted against REE-index for all peat samples investigated.

The results so far correlate well between the different sites both on a regional, and a global scale. There is also evidence that there is a c. 1000-1250 year cyclicity in the influx of cosmic material to Earth at least in the more modern end of the graphs of REE and Co indexes. This cyclicity appears more prominent in the REE index. High peaks $(\mathrm{H}$ and $\mathrm{L}$ figures are numbering) are for example found around 200-700 (H12), 900 (H11), 1250 (H10), 1400-1500 (H9), 1600-1700 (H8), 2400-2800 (H7), 3500-3700 (H6), 4100-4400 (H5) and 4700-5300 (H4) years BP. A broad high peak exists between c. 5800-7000 BP with relative peaks of 5700-6000 (H3) and c. 6400-7000 (H2). The highest peak in the whole time series is centred over c. 8100-8700 BP (H1) followed by a minor trough (relatively of c. 9000-9800 BP (L0). A high broad peak also persists from c. $10000 \mathrm{BP}$ to the bottommost layers at $14000 \mathrm{BP}$, however with a relative peak of 9300-11 000 BP. However, it should be noted that the 800014000 BP graph is based only on a few mires in Ireland and Tierra del Fuego. The best coverage including all 21 mires measured is 0-5000 BP. Notable troughs are the c. 700-1400 (L7), 1700-2400 (L6), 2800-3500 (L5), 3900-4100 (L4), 4400-4700 (L3), 5300-5700 (L2) and the trough mentioned above of 9000-9800 BP (L0). The most prominent feature in the REEindex development is the dramatic decline which started around $8100 \mathrm{BP}$ ending up at the relatively low platform of 7500-5800 BP(L1). 
Geografiska Annaler Special Issue for SL - Lars Franzén and Roger Cropp

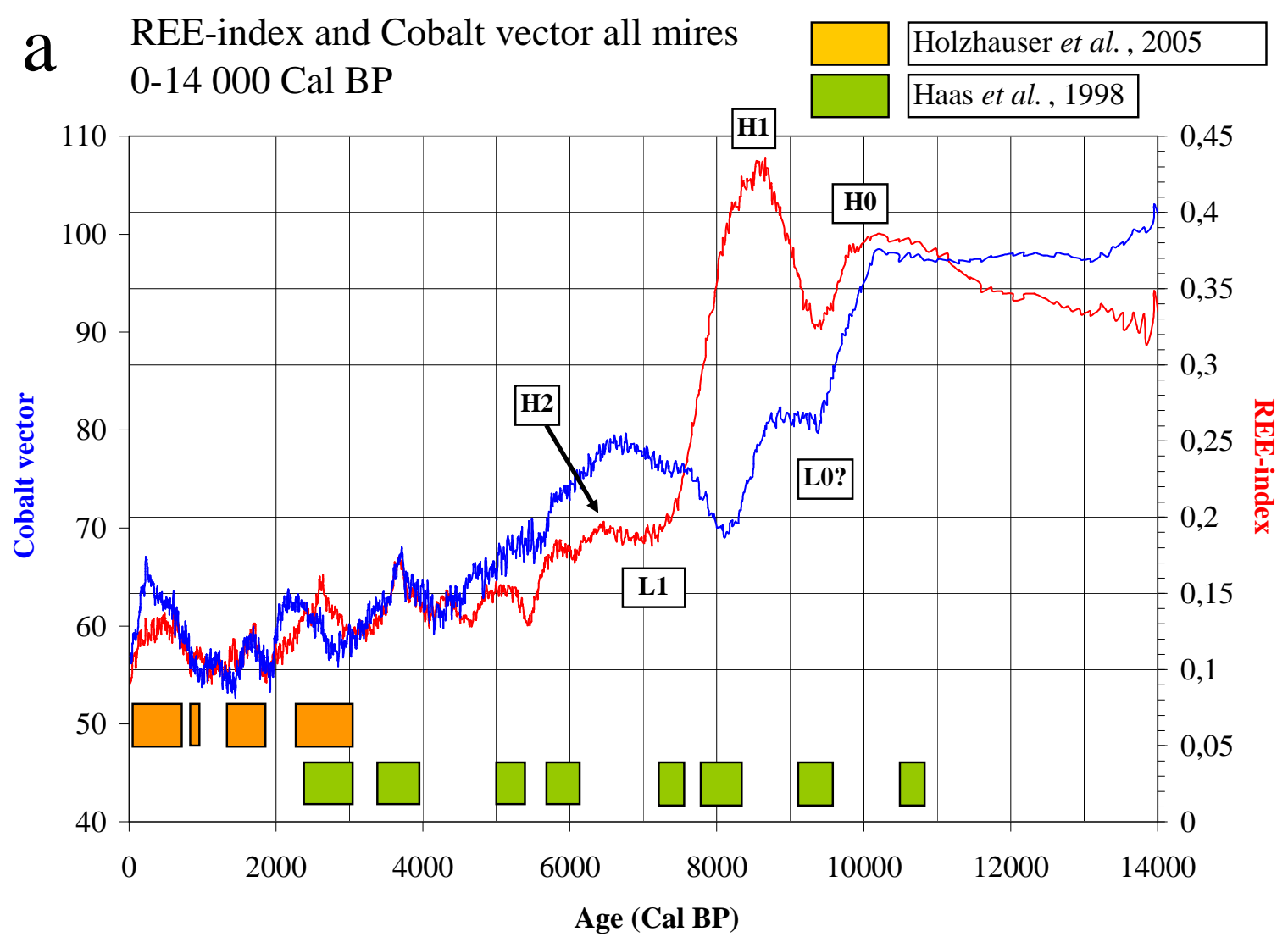

b REE-index and Cobalt vector all mires 0-7000 Cal BP
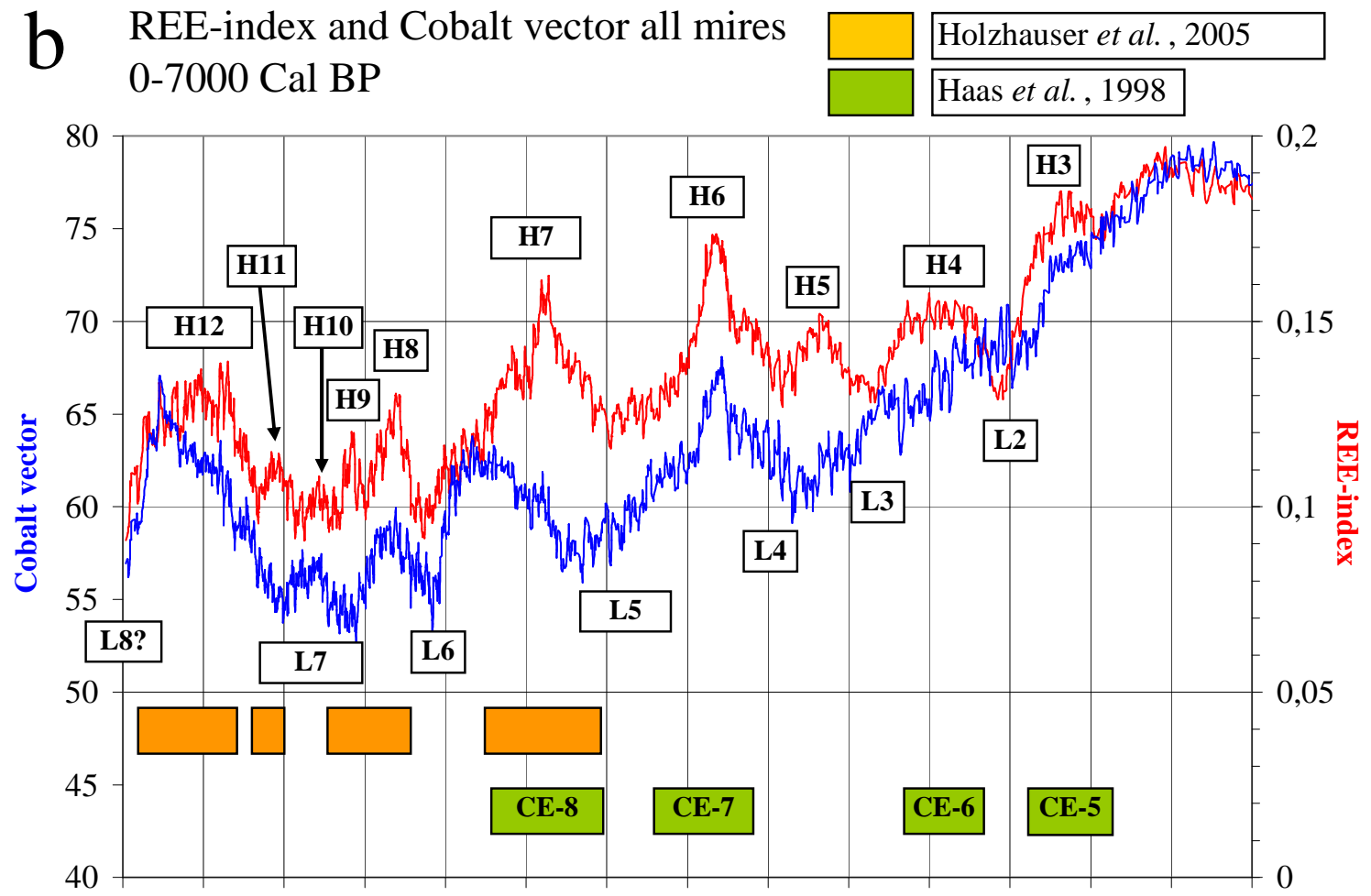

$0 \quad 5001000150020002500300035004000450050005500600065007000$ Age (Cal BP) 
Fig. 14. REE (red) and Cobalt (blue) indexes combined for the 21 raised bogs studied in Sweden, Ireland and Tierra del Fuego. Fig 14a shows the development from 14000 BP to present whereas 14b shows, with better resolution, the development from $7000 \mathrm{BP}$ to present. Orange boxes are periods of glacier advance in westcentral Europe according to Holzhauser et al. (2005), whereas green boxes show cold periods in central Europe according to Haas et al. (1998). White $\mathrm{H}$ and $\mathrm{L}$ boxes show periods of high and low cosmic indexes, respectively.

\section{Synchronicity between cosmic dust influxes and Holocene climate variations}

A sequence of rapid cooling events during the Holocene period (the Earth's recent climate history since the end of the last ice age about 12,500 years ago) have been observed in ocean floor sediment cores extracted from opposite sides of the North Atlantic Ocean (Bond et al. 1997). Bond et al.'s data revealed strong cyclicity in the occurrence of these events, with recurrences observed at an average period of $1374 \pm 502$ years for the nine events detected during the Holocene. Similar events detected during the glacial period back to about 30,000 years before present had a periodicity of $1536 \pm 563$ years, indicating that these quasi-periodic events are independent of the state of the climate (Bond et al. 1997).

Combined, these events have a similar periodicity to Dansgaard-Oeschger events that occurred during the last glacial period (approximately 120,000 - 12,000 years before present) (Dansgaard et al. 1993) and which have been observed in many records of paleoclimatic data. These persistent cycles are estimated to occur at intervals of $1470 \pm 176$ years with a regularity that appears to preclude their being the result of internal cycles within the Earth's climate system, but rather the manifestation of an external forcing such as an orbital cycle (Rahmstorf 2003). However no orbital cycles with this periodicity are known (Rahmstorf 2003, Braun et al. 2005).

Simulations using a coupled climate system model have reproduced the 1470 year Dansgaard-Oeschger cycle during the last glaciation by forcing the model with the superposition of two solar cycles with periods of 88 and 205 years, the Gleissberg and DeVries-Suess cycles respectively (Wagner et al. 2001, Peristykh and Damon 2003). The model simulations implemented these solar forcings as periodic influxes of freshwater to the North Atlantic Ocean in cycles of 86.5 and 210 years. However, the model was not able to simulate the millennial-scale cycles observed in the Holocene period (Braun et al. 2005)

Although an estimated 40,000 tonnes of cosmic dust falls to Earth each year, the temporal variability of the cosmic dust flux is poorly known (Winckler and Fischer 2006). The preliminary data obtained here is significant in that it reveals the presence of a strong $1250 \pm$ 50 year cycle in the influx of cosmic dust to the Earth. The period of this cycle is very close to the period of the cooling cycle observed by Bond et al. (1997). Further, the peaks of cosmic dust influx coincide with peaks in ice-rafted debris (IRD) observed by Bond et al. (1997)), with significant climatic events such as the "Little Ice Age" of approximately 400 years ago and with the major cooling event recorded 8200 years ago in many paleoclimatic data (Stager and Mayewski 1997)) (Table 2).

Table 2. Paleoclimatic events recorded by Bond et al. (1997) and Franzén and Cropp (in this volume) and coincident methanesulphonate (MSA) peaks extracted from the Greenland Icecore Project data (GRIP). 
Geografiska Annaler Special Issue for SL - Lars Franzén and Roger Cropp

\begin{tabular}{|c|c|c|c|}
\hline $\begin{array}{l}\text { Coincident GRIP } \\
\text { Ice-core MSA peaks } \\
\text { Legrand et al. 1997 }\end{array}$ & $\begin{array}{l}\text { Bond et al. (1997) } \\
\text { IRD events }\end{array}$ & $\begin{array}{l}\text { Franzén and Cropp cosmic } \\
\text { dust events (this paper) }\end{array}$ \\
\hline \multicolumn{4}{|c|}{ Years Before Present (approximately) } \\
\hline 600 & - & $200-700$ & H12 \\
\hline- & - & 900 & H11 \\
\hline 1250 & - & 1250 & H10 \\
\hline- & 1400 & $1400-1500$ & H9 \\
\hline- & - & $1600-1700$ & H8 \\
\hline- & 2800 & $2400-2800$ & H7 \\
\hline- & - & $3500-3700$ & H6 \\
\hline 4100 & 4200 & $4100-4400$ & H5 \\
\hline- & - & $4700-5300$ & H4 \\
\hline 5700 & 5900 & $5700-6000$ & H3 \\
\hline 6900 & - & $6400-7200$ & H2 \\
\hline 8100 & 8100 & $8100-8700$ & H1 \\
\hline 9350 & - & $9300-11000$ & H0 \\
\hline
\end{tabular}

Also shown in Table 2 are paleoclimatic records of atmospheric methanesulphonate (MSA) concentrations extracted from Greenland ice cores (Legrand et al. 1997). MSA is the end product of atmospheric reactions involving dimethylsulphide (DMS) produced by marine ecosystems and hence is a useful indicator of marine biological activity during the Holocene. Although the covariance between MSA concentrations and climate remains unresolved, some of the events observed in the Bond et al. (1997) and data presented here closely coincide with peaks of MSA evident in the Greenland ice-core data (Table 2) suggesting that in several cases significant increases in marine primary production accompanied the cosmic dust deposition and cooling events.

The high peaks of cosmic influx to the ombrotrophic peatlands correlate surprisingly well with Holocene cold spells as recorded in a large number of other records e.g. Haas et al. (1998) and Holzhauser et al. (2005). The latest "cosmic pulse" (H12) is centred over the peak of the Little Ice Age (Fig. 14b). Regarding the obvious correlation between high cosmic indices and climate detoriation one could either argue that climate affects the composition of dust in peat, or vice versa, that climate is affected by the mechanism depositing microspherules and elements with a cosmic signature to peat bogs. The various high and low peaks will be discussed in detail in a coming paper, however, the marked peak centred over $8500 \mathrm{BP}$ must be commented.

\section{The "Post Glacial Shock"}

Looking at the 14,000 years' graph (Fig. 14a) the most striking REE peak (H1) occurs at between 8700-8100 BP. In peat stratigraphies that extend this far down (e.g. the Fallahogy and Harberton bogs) the REE-index is peaking and their chondrite normalized graphs show up as horizontal lines (Fig. 12d). Only a few iron spherules were recovered from these bogs but quite a few glassy types were found. This is the only notable event in the Greenland ice isotopic record for that period, and is recorded as a $1.5 \%$ negative shift in the $\delta^{18} \mathrm{O}$, equivalent to a $4-8^{\circ} \mathrm{C}$ drop in air temperature which lasted for 200 years (Alley et al. 1997, Labeyrie et al. 2003). According to Thomas et al. (2007) the cold event $8200 \mathrm{BP}$ as observed in central 
Greenland is a $160.5 \mathrm{yr}$ period of reduced isotopic ratios, within which there is a central event of $69 \mathrm{yr}$ when values were significantly below the Holocene average. Long et al. (2006) considered the 'GH-8.2 event' was associated with a $5-7^{\circ} \mathrm{C}$ fall in mean annual air temperature over the centre of the Greenland ice sheet, and a similar drop in mean temperatures of between 0.6 and $1.2^{\circ} \mathrm{C}$ was recorded for the Scandinavian mountains (Dahl and Nesje 1996).

The timing of this episode also coincides with the most prominent events in both European lake isotopic records and speleothem trace element records occurring at about $8200 \mathrm{BP}$ (von Grafenstein et al. 1998, Barber et al. 1999, Baldini et al. 2002) when according to these records annual mean temperatures dropped by as much as $2{ }^{\circ} \mathrm{C}$ in mid-Europe, and the European alpine timberline fell by about $200 \mathrm{~m}$ (Wick and Tinner 1999). In western Norway, a whole series of glacial episodes were recorded between 8550-7150 BP (Nesje et al. 2006), with most of these occurring in the CDI's H1 record centred over $8200 \mathrm{BP}$ and commonly known as the "Finse Event" (Shakesby et al. 2004). Karlén et al. (1995) also reported a cold period in Northern Sweden at this time. Further, one of the most significant cool periods in the Swiss Alps occurred at $7700-8200$ BP (Heiri et al. 2003), and the H1 CDI excursion corresponds approximately to the Haas et al. (1998) CE-3 (7800-8400 BP) cold and humid period of central Europe.

A centennial-scale cooling around $8200 \mathrm{BP}$ was also recorded in the Eastern Alps (Kofler et al. 2005). In the western part of Austria the event, when glaciers advanced to a position beyond its Little Ice Age limit and mean annual temperatures were $1.5-2^{\circ} \mathrm{C}$ lower than today, is known as the "Kromer Stadial" (Kerschner et al. 2006). In the Holzmar lake sediment record of Germany, the $8200 \mathrm{BP}$ event is the most prominent and longest of a series of shortterm climatic oscillations (Prasad et al. 2006). High lake levels were recorded 8200-8300 BP in the French Pre-Alps (Magny et al. 2003) and in Poland during the period of 7700-8400 BP (Starkel et al. 1996). A 200-year negative excursion of $\delta^{18} \mathrm{O}$ in biogenic carbonate from Ammersee in southern Germany (von Grafenstein et al. 1998) is another observation among the lacustrine records, and similar observations have also been made in northern Sweden (Rosén et al. 2001) and Italy (Ramrath et al. 2000). A lake sediment study from western Ireland indicated a reduction in summer temperatures by $6^{\circ} \mathrm{C}$ at about $8000 \mathrm{BP}$ (Ahlberg et al. 2001).

Leuschner et al. (2002) reported on reduced growth rate and reduced germination of German bog oak stands between 8000 and 8200 BP, indicative of cooler and/or drier conditions. The $8200 \mathrm{BP}$ event may be related to a significant decrease of SST in the Norwegian Sea (Klitgaard-Kristensen et al. 1998). According to Alley et al. (1997) the spatial pattern of terrestrial and marine changes of the $8200 \mathrm{BP}$ event is similar to that of the Younger Dryas. In northern Europe increasing in flooding frequency c. 8000-8500 BP was recorded in e.g. Poland (Starkel 1984), southern Germany (Becker and Schirmer 1977) and Norway (Sønstegard and Mangerud 1977). Rapid cooling triggered the downslope movement of the tree line in NE British Columbia, Canada (Pisaric et al. 2003). The atmosphericsurface ocean system hence affected over much of the North Atlantic and surrounding continents in a similar way as during the Younger Dryas period, however, with a lower amplitude (Labeyrie et al. 2003). Increased of precipitation and cold conditions in NE North America from lake deposit studies at c. $8200 \mathrm{cal}$ yr BP (Shuman et al. 2006). According to Turunen and Turunen (2003) peatlands started to form and expanded rapidly over the surroundings in oceanic British Columbia, Canada between 7500 and 8300 BP.

The about 8200 year cooling did not only affect the North Atlantic region but may have been a worldwide climate trauma (Stager and Mayewski 1997). Thus cooling is indicated in the New Zealand Southern Alps, with small advances of the mountain glaciers at about 8000 years BP (Salinger and McGlone 1989). A distinct phase of aridity was recorded from dune 
field activation data of tropical northern Australia at c. 8200 BP (Nott et al. 1999) and from Tibet Yu et al. (2006) emphasized an extremely cold period with increasing winter monsoon and decreasing summer monsoon at $8200 \mathrm{BP}$ Lake records from the south Sahel of central Africa indicate extremely dry conditions during this time (and probably also during other cool but less dramatic events of this kind) (Street-Perrot and Perrot 1990, Gasse and Van Campo 1994) and in Ethiopia a predominantly humid early Holocene was interrupted by a short period of aridity from around $8500 \mathrm{BP}$ (7600 to $7900{ }^{14} \mathrm{C}$ yrs BP) (Lamb et al. 2000). From semi-arid eastern Anatolia, Turkey, Wick et al. (2003) recorded a regional climate change with increased precipitation at $8200 \mathrm{BP}$.

Dating this far back in human history cultural evidence for this event are scarce, but in the Middle East according to Weiss and Bradley (2001) a roughly 200-year long drought forced the abandonment of agricultural settlements in northern Mesopotamia. Unfavourable climatic conditions at about $8200 \mathrm{BP}$ and $4200 \mathrm{BP}$ have also been invoked as the cause of the abandonment of Neolithic farming towns in the Jordan valley and the collapse of the Akkadian civilisation, respectively (e.g. Cullen et al. 2000, DeMenocal 2001, Mithen 2003, Robinson et al. 2006). Weninger et al. (2006) concluded that the $8200 \mathrm{BP}$ aridity event triggered the spread of early farmers, by different routes, out of West Asia and the Near East into Greece and Bulgaria.

The 8200 event is hence observed in a large number of high-resolution climate proxies, notably in the Northern Hemisphere. However, according to Fisher and Koerner (2003) the $8200 \mathrm{BP}$ event is not apparent in the Antarctic or tropical ice-cores and Morrill et al. (2003) were not able to confirm this event from a compilation of a long row of Asian climate records. The event, in many cases, corresponds to markedly cold and arid conditions; however, the mechanisms behind this event are still to be solved. Rohling and Pälike (2005) noted that in many of the Asian records, the 8200 BP event was part of a longer anomaly that lasted 400600 years, whereas a sharp event of c. 150 years duration was observed in Greenland (Staubwasser and Weiss 2006). The drainage of glacial lakes Agassiz and Ojibway into the Northern Atlantic at about 8470 BP has been brought forward as a possible candidate (e.g. Weninger et al. 2006). Barber et al. (1999) have shown evidence supporting a catastrophic drainage just prior to the cold event but according to Labeyrie et al. (2003) there is no direct indication for an associated meltwater spike from ocean sediments records of that period. Other possible forcing mechanisms include e.g. fluctuations in solar activity (Muscheler et al. 2004, Kofler et al. 2005). Our record of CDI's dominating the influx to ombrotrophic peatlands at this time interval strongly support this latter idea of a cosmic or solar background to this outstanding climatic event.

\section{Cosmic dust and climate}

If there is a connection between cosmic dust deposition and climate, the mechanisms for this are not yet fully understood. The first thoughts here, suggested by Clube and Napier (1990), were that an increased amount of dust entering the atmosphere could cause dimming and direct shading of incoming shortwave radiation, thereby cooling the Earth. Other possibilities are indirect effects of cosmic dust i.e. cosmic dust could possibly trigger other systems down on Earth resulting in climate changes. The first impulses in this latter direction were given as a reply to a small note in New Scientist by Mr. Risto Isomäki of Finland (Isomäki 2002). He suggested that the additional supply of material from extraterrestrial sources could affect life in surface oceans, in particular remote areas with a shortage of other compounds, aside from the major constituents of sea-water. It is widely recognized that the productivity in large parts of the modern open ocean is limited by the availability of Fe (Martin et al. 1990, Morel et al. 
1991). Other biologically essential trace metals, such as $\mathrm{Zn}$ and Co may also be important in regulating the relative amounts of biogenic carbonate and organic carbon production. (Schulz et al. 2004, Dalai et al. 2006).

Extraterrestrial bodies, whatever their size, would be affected by the atmospheric entrance. Smaller particles would likely be totally digested by heating, whereas larger fragments and meteorites would burn partly. In either case, this would leave traces in the form of ablation spherules and much smaller particles in the form of fume. Whereas the core meteorites and spherules would fall to the ground in the time span of minutes, hours or days the gassed-off elements in the size of single atoms or molecules may take weeks, months or years to enter the ground (e.g. Hunten et al. 1980, Rietmeijer and Jenniskens 1998). However, Plane et al. (2004) noted the role of ice particles polar mesospheric clouds in removing meteoric iron atoms from the upper atmosphere. They speculated that once adsorbed onto the ice particles, the meteoric iron may drift to warmer latitudes, and the ice particles would sublimate leaving behind concentrated residual iron particles. Such particles may well fall to earth much faster than if they remained as individual atoms. Larger particles landing in oceans would likely sediment quickly whereas those smallest fragments could have a long residence time near the surface (e.g. Honjo 1996), thus being available to various life-forms such as algae and other parts of the plankton flora and fauna.

Trace metal fertilization of the surface ocean by extraterrestrial dust represents a viable alternative to other, more established explanations to rapid cooling and the initiation of glaciations. Calculations suggest that today interplanetary dust particles may play an important control role in the modern ocean by supplying significant amount of bioavailable Fe; up to $300 \%$ of aeolian Fe flux and $20 \%$ of the upwelling Fe flux to the Southern Ocean (Johnson 2001).

\section{Possible climate regulating mechanisms}

Several mechanisms by which influxes of cosmic dust could affect climate have been proposed. Clube and Napier (1990) suggested that veils of cosmic dust may directly contribute to cooling by preventing solar radiation from reaching the Earth's surface, much in the same manner that ash from volcanic eruptions has been observed to cool the planet. However, it appears that the influence of the iron contained in cosmic dust on the growth of phytoplankton in the oceans may provide a more influential mechanism for cooling the planet.

Iron is a micronutrient required for photosynthetic reactions within chloroplasts. Martin (1990) proposed that many oceanic phytoplankton, especially those in the high nutrient - low chlorophyll (HNLC) regions of the world's oceans (the north-western and eastern equatorial Pacific Ocean and the entire Southern Ocean), were limited by the availability of iron. The principal known source of new iron to the oceans is aeolian terrestrial dust (Duce and Tindale 1991). The majority of iron deposition into the ocean currently occurs in the Northern Hemisphere and is principally associated with dust export from major arid regions such as the Sahara and Taklamakan Deserts (Prospero et al. 2002). The North Atlantic and North Pacific Oceans receive $48 \%$ and $22 \%$ of global iron deposition to the oceans respectively. In contrast, the South Atlantic and South Pacific Oceans receive only 4\% and 2\% respectively. The Indian Ocean receives 18\% (principally in the Arabian Sea) and the Mediterranean Sea receives 4\%. The polar regions in both hemispheres receive very low iron inputs, with the Arctic receiving only $0.9 \%$ and the Antarctic $0.5 \%$ (Gao et al. 2001). Many other nutrients required by phytoplankton for growth may also be deposited with aeolian dust, and again, the Northern Hemisphere oceans receive the majority of these inputs ((Duce et al. 1991)). 
Fung et al. (2000) noted that iron in terrestrial dust underwent reactions in the atmosphere and ocean during its transport and deposition to the ocean so that a substantial proportion (1$10 \%$ ) was soluble and immediately available to phytoplankton. Johnson (2001) has suggested that the levels of iron fertilisation associated with current cosmic dust deposition levels could be quite important to global ocean biogeochemistry. Recent experiments have confirmed the role of iron in limiting phytoplankton production in large regions of ocean (Coale et al. 1996, Boyd et al. 2000). These iron-limited HNLC regions comprise approximately $30 \%$ of the World Ocean and include the Southern Ocean (de Baar and Boyd 2000).

There are two known mechanisms by which increased phytoplankton productivity could influence climate. One is by the direct draw-down of carbon from the atmosphere and its subsequent export to and storage in the deep ocean as particulate organic carbon (Watson et al. 2000). The potential for iron contained in aeolian terrestrial dust deposited in the oceans to affect climate in this manner was recently assessed by Kohfeld et al. (2005), who concluded that while iron-fertilisation of ocean ecosystems might account for $30-50 \mathrm{ppm}$ of atmospheric $\mathrm{CO}_{2}$ draw-down during the last glacial period, all known terrestrial forcings on marine biology could only account for up to half of the observed drawdown. Dalai et al. (2006) proposed the "speculative hypothesis" that higher cosmic dust flux in the Late Eocene may have contributed to the global cooling and early Oligocene glaciation by supplying bioessential trace elements to the oceans and thereby resulting in higher ocean productivity, enhanced burial of organic carbon and draw down of atmospheric $\mathrm{CO}_{2}$. Blain et al. (2007) concluded that long-term fertilization by iron and macronutrients may have a more significant effect on atmospheric carbon dioxide than previously thought.

A second mechanism was proposed by Charlson et al. (1987). This hypothesis noted that some dimethylsulphide (DMS) produced by marine planktonic ecosystems was ventilated to the atmosphere where it formed a significant source of cloud condensing nuclei $(\mathrm{CCN})$ over the oceans. Charlson et al. suggested that the aerosols resulting from biogenic DMS emissions could have a direct effect on the solar radiative forcing experienced by the Earth through scattering, absorption and reflection and could also lead to increased cloud formation that would increase the Earth's albedo and hence further cool the planet. Recent research has provided much support for these hypotheses, with recent estimates that the cooling effect due to dimethylsulphide may be up to $40 \%$ of the anthropogenic greenhouse forcing in Polar Regions (Gabric et al. 2003). Similarly, a recent review by Jickells (2006) stresses the importance of iron in terrestrial dust in climate studies.

DMS is an ecosystem product. Many species of marine phytoplankton synthesise dimethylsulphoniopropionate (DMSP), the precursor to DMS. However, most DMSP that is converted to DMS is done so by ecosystem processes that occur outside the phytoplankton cell (Simo 2001). In addition to the climatic role postulated for DMS by the CLAW hypothesis, DMSP is a compatible solute that can protect cells from the osmotic effects of seawater and the effects of freezing, may deter predation by zooplankton, may act as an antioxidant, and has also been proposed to assist in the long range dispersal of marine phytoplankton ((Wolfe et al. 1997, Hamilton and Lenton 1998, Kiene et al. 2000, Sunda et al. 2002)).

If we look at the potential DMS production from CDI events from an aspect of response time, we could expect the CDI/DMS coupling to have very rapid effects. The response time of phytoplankton stocks to iron fertilisation has been estimated at about one week (Wong et al. 2006) so on the paleoclimate time scales we are looking at the effects are effectively instantaneous. The time lag between a phytoplankton bloom and the subsequent release of DMS to the atmosphere has also been estimated to be of the order of one week, resulting in an expected two week delay between the deposition of iron and the subsequent ventilation of DMS (Turner et al. 1996, 2004). The atmospheric processes involving DMS are poorly 
understood (Ayers and Gillett 2000) but may be relatively rapid, as short as six hours (Lin and Chameides 1993).

Increased primary productivity in the ocean would also rapidly affect atmospheric carbon dioxide concentrations. The recent SERIES experiment in the northern Pacific Ocean (Wong et al. 2006) documented carbon drawdown from the atmosphere and export to the deep ocean at around $2-3$ weeks after fertilization. Atmospheric drawdown of $0.09 \mathrm{~mol} / \mathrm{m}^{2}$ and export of $0.43 \mathrm{~mol} / \mathrm{m}^{2}$ were measured, but the dissolved inorganic carbon take-up by phytoplankton of $1.81 \mathrm{~mol} / \mathrm{m}^{2}$ suggests that carbon drawdown from the atmosphere would have continued after the completion of the experiment. This paper also includes a comparison of carbon drawdown measured by 8 various iron fertilization experiments that range from $50 \times 10^{6} \mathrm{gC}$ to $3880 \mathrm{x}$ $10^{6} \mathrm{gC}$. Levasseur et al. (2006) showed a three-fold increase in DMSP (the precursor of DMS) in the same experiment. However DMS also showed an increase about 10 days after fertilization, but not significantly different to that of outside the patch - it seems that external environmental factors overwhelmed the iron-induced response.

If viewed in a longer time perspective there is some evidence that significant carbon drawdown from the atmosphere by phytoplankton blooms may take some months to occur after fertilisation. Iron fertilization may also eventually cause the phytoplankton to exhaust the other nutrients in the ocean mixed layer, halting the blooms (Marchetti et al. 2006). However, the widespread rapid cooling of surface ocean layers due to shading by DMSinduced clouds may cause the average mixed layer depth to deepen and entrain more nutrients from below, so global iron fertilisation may increase the total nutrients in the upper ocean and stimulate primary productivity over longer time scales. It may be that sustained (decadeslong) cosmic iron deposition results in the pumping of other nutrients from the deeper ocean to the surface layers, providing a positive feedback and implying that the influence of the dust deposition will gradually increase over decades.

\section{Conclusions}

The present point of view is that the climate during the Pleistocene might be regulated by two fundamentally different mechanisms i.e. one long term regulation based on the irreversible interglacial carbon sequestering into the peat reservoir, starting at the beginning of each interglacial, and a short term regulation based on the cyclical recurrence of cosmic dust influx. The long term regulator which acts in the time scale of $10^{4-5}$ years is decisive for the regular occurrence of glaciations and interglacials, whereas the short term regulator would be responsible for the smaller century to millennium scale variations, and possibly act as an igniting mechanism at the onset of a new glacial pulse.

The connection between high cosmic dust influx and falling temperatures is yet not fully understood but a possible candidate is the fertilization of surface waters of remote ocean areas. The process possibly involves the formation of DMS and the subsequent cloud formation, leading to a decreased influx of shortwave radiation to the Earth (Charlson et al. 1987). In the case of low rates of fertilization the opposite situation will occur with rising temperatures. It is possible that short term $\mathrm{CO}_{2}$ variations are also involved but in our opinion, DMS mechanisms alone could serve as the leading catalyst in the cosmic dust/climate interface. The rapid rate of cooling/warming that has occurred several times during the Holocene suggests that the variation in atmospheric DMS would provide a feasible mechanism for change, with a response time in the range of decades or even single years (i.e. much more sensitive than the relatively inert system of $\mathrm{CO}_{2}$ or other direct greenhouse gas variations). The variations in flux observed here may well have had, but also presently have, a significant impact on marine productivity and flux of cloud-forming substances, especially in 
regions where $\mathrm{Fe}$ and trace element deficiency limit primary production. The low periods, in contrast to the high, would mean a low rate of cosmic dust influx and hence a lower rate of DMS production, less cloud formation and rising global surface temperatures.

The mechanism behind the varying influx of cosmic dust to Earth is another delicate matter. The last CDI maximum coincided with the Maunder sunspot minimum whereas the last cosmic low was centred over the Medieval sunspot maximum. This implies on a connection between cosmic dust influx and solar activity. Svensmark and Friis-Christensen (1997) proposed a "Cosmic ray-cloud cover" hypothesis and Svensmark recently proposed the new term "Cosmoclimatology" (Svensmark 2007), suggesting that cosmic ray flux, modulated by solar activity, may modify global cloud cover and thus global surface temperature, an hypothesis which has been questioned (e.g. Sun and Bradley 2002, de Jaeger and Usoskin 2006). We suggest that solar activity might shield the Earth from CDI during solar maxima in a similar manner to that in which it shields from galactic cosmic rays. The reversed situation might occur at solar minima during which periods larger amounts of cosmic dust might reach the Earth with subsequent DMS production and associated cloud formation. Similar ideas to Svensmark have e.g. been proposed by Shaviv and Veizer (2003) claiming a low frequency Phanerozoic climate cycle $(\approx 135 \pm 9$ m.y.). According to Shaviv and Veizer, cold periods correspond with encounters with spiral arms of the Milky Way, and the resulting increases in the cosmic-ray flux. Whereas Svensmark claims subatomic particles, the particles and geochemical signals we are measuring might be the natural condensate of supernova matrix (Clayton et al. 1997), or even our "gravitational catch" while passing through regularly occurring particle-dense parts/rooms of space during the cosmic year.

Finally, from a human point of view, the millennium scale fluctuations described here might be the cause of the rise and fall of cultures. Periods of low cosmic influx would lead to the rise and bloom of civilizations whereas the periods of high cosmic influx would lead to the decline and final collapse of these cultures hence leading us into what has been described as "Dark Ages" of the past. If the hypothesis is right, we are just leaving the latest of such "Dark Ages", i.e. The Little Ice Age, and entering into a new "Bright Age" in the series of natural millennial oscillations.

\section{Acknowledgements}

Over the years this study has been supported financially by a long row of grants i.e. from The Swedish Research Council (VR), The Swedish Foundation for International Cooperation in Research and Higher Education (STINT), The Swedish Peat Research Foundation, The Swedish Academy of Sciences (Margit Althin's Foundation, Hiertha-Retzius Foundation), The Royal Society of Arts and Sciences in Göteborg (KVVS) and The Göteborg University Foundation for Teachers' Travels and Research. The first author also acknowledges the staff at CADIC CONICET in Ushuaia, Argentina for their support during the Tierra del Fuego peat sampling.

Lars G. Franzén, PhD., Department of Earth Sciences, Göteborg University, P.O. Box 460, SE-405 30 Göteborg, SWEDEN, lars@gvc.gu.se

Roger A. Cropp, PhD, Centre for Environmental Systems Research, Griffith School of Environment, Griffith University, Nathan, 4111, AUSTRALIA, r.cropp@griffith.edu.au, (coauthor in the Glacial Pulse Trigger part) 


\section{References}

Aaby, B. 1990: Geologi og mosedannelse i Store Vildmose området. Miljöministeriet: Landet och loven (In Danish).

Ahlberg, K., Almgren, E. Wright J., H.E. and Ito, E., 2001: Holocene stable-isotope stratigraphy at Lough Gur, County Limerick, Western Ireland. The Holocene 11(3):367372.

Alibo, D.S. and Nozaki, Y., 1999: Rare earth elements in seawater: Particle association, shalenormalization, and Ce oxidation. Geochimica et Cosmochimica Acta 63: 363-372.

Alley, R.B., Mayewski, P.A. Sowers, T. Stuiver, M. Taylor K.C. and Clark, P.U. 1997: Holocene climatic instability: A prominent, widespread event 8200 years ago. Geology, 25: 483-486.

Almquist-Jacobsen, H. and Foster, D.R. 1995: Toward an integrated model for raised-bog development: theory, and field evidence. Ecology 76: 2503-2516.

Ayers, G. P., and Gillett, R.W. 2000: DMS and its oxidation products in the remote marine atmosphere: implications for climate and atmospheric chemistry. Journal of Sea Research, 43: 275-286.

Baldini, J.U.L., McDermott, F. and Fairchild, I.J. 2002: Structure of the 8200-year cold event revealed by a speleothem trace element record. Science 296: 2203-2206.

Barber, D.C., Dyke, A. Hillaire-Marcel,C. Jennings, A.E. Andrews, J.T. Kerwin, M.W. Bilodeau, G. McNeely, R. Southon, J. Morehead M.D. and Gagnon, J.M., 1999: Forcing of the cold event of 8,200 years ago by catastrophic drainage of Laurentide lakes. Nature, 400, 344-347.

Becker, B. and Schirmer, W., 1977: Paleoecologic study of the Holocene valley development of the river Main, Southern Germany. Boreas 6(4): 303-321.

Björck, S., Malmer, N., Hjort, C., Sandgren, P, Ingolfsson, O., Wallén, B., Smith, R.I.L., and Jonsson, B.L., 1991: Stratigraphic and paleoclimatic studies of a 5000-year-old moss bank on Elephant Island, Antarctica. Arctic Alpine Research 23: 361-374.

Blain, S. et al., (47 authors) 2007: Effect of natural iron fertilization on carbon sequestration in the Southern Ocean. Nature 446: 1070-1075.

Bond, G., Showers, W. Cheseby, M. Lotti, R. Almasi,P., deMenocal, P. Priore, P. Cullen, H. Hajdas, I and Bonani, G., 1997: A pervasive millennial-scale cycle in North Atlantic Holocene and Glacial Climates., Science, 278, 1257-1266.

Boyd, P. W., Watson, A.J., Law, C.S., Abraham, E.R., Trull, T., Murdoch, R., Bakker, D.C.E., Bowie, A.R., Buesseler, K.O., Chang, H., Charette, M., Croot, P., Downing, K., Frew, R., Gall, M., Hadfield, M., Hall, J., Harvey, M., Jameson, G., LaRoche, J., Liddicoat, M.I., Ling, R., Maldonado, M.T., McKay, R.M., Nodder, S., Pickmere, S., Pridmore, R., Rintoul, S., Safi, K., Sutton, P., Strzepek, R. Tanneberger, K., Turner, S.M., Waite, A. and Zeldis, J., 2000. A mesoscale phytoplankton bloom in the Southern Ocean stimulated by iron fertilization. Nature 407: 695-702.

Boynton, W.V., 1984: Geochemistry of rare earth elements: meteorite studies. In: Henderson, P. (Ed.), Rare earth element geochemistry. Elsevier, Amsterdam, p. 63-114.

Braun, H., Christ, M., Rahmstorf, S., Ganopolski, A., Mangini, A., Kubatzki, C., Roth, K., and Kromer, B., 2005: Possible solar origin of the 1,470-year glacial climate cycle demonstrated in a coupled model. Nature, 438: 208-211.

Brownlee, D.E., 1981: Extraterrestrial components. In: Emiliani, C. (Ed.), The Oceanic lithosphere. John Wiley, New York, p. 733-762.

Calder, N., 1974: The weather machine and the threat of ice. BBC, London, $143 \mathrm{p}$.

Carusi, A., Coradini, A. and Fulchignoni, M., 1972. Genesis of the structures of the black magnetic spherules. Periodico di Mineralogia, 41: 363-371. 
Ceplecha, Z., 1996: Luminous efficiency based on photographic observations of the Lost-City fireball and implications for the influx of interplanetary bodies onto Earth. Astronomy and Astrophysics, 311: 329-332.

Charlson, R.J., Lovelock, J.E., Andrae, M.O. and Warren, S.G., 1987: Oceanic phytoplankton, atmospheric sulphur, cloud albedo and climate. Nature 326: 655-661.

Clube, V. and Napier, B., 1990: The cosmic winter, Blackwell, Oxford, 307 p.

Coale, K. H., Johnson, K.S., Fitzwater, S.E., Gordon, R.M., Tanner, S., Chavez, F.P., Ferioli, L., Sakamoto, C., Rogers, P., Millero, F., Steinberg, P., Nightingale, P., Cooper, D., Cochlan, W.P., Landry, M.R., Constantinou, J., Rollwagen, G., Trasvina, A., and Kudela, R., 1996. A massive phytoplankton bloom induced by ecosystem-scale iron fertilization experiment in the equatorial Pacific Ocean. Nature 383: 495-501.

Cornell, D. H., 1993: Rare earths from supernova to superconductor. Pure \& Applied Chemistry 65 (12): 2453-2464.

Cropp, R.A., 2002: A biogeochemical modelling analysis of the potential for marine ecosystems to regulate climate by the production of dimethylsulphide. Thesis, School of Australian Environmental Studies, Griffiths University, Australia.

Cullen, H.M., deMenocal, P.B., Hemming, S., Hemming, G., Brown, F.H., Guilderson, T. and Sirocko, F., 2000: Climate change and the collapse of the Akkadian Empire; evidence from the deep sea, Geology 28: 379-382.

Dahl, S.O. and Nesje, A., 1996: A new approach to calculating Holocene winter precipitation by combining glacier equilibrium-line altitudes and pine-tree limits: a case study from Hardangerjøkulen, central southern Norway. The Holocene 6(4): 381-398.

Dalai, T.K., Ravizza, G.E. and Peucker-Ehrenbrink, B., 2006: The Late Eocene ${ }^{187} \mathrm{Os} /{ }^{188} \mathrm{Os}$ excursion: Chemostratigraphy, cosmic dust flux and the Early Oligocene glaciation. Earth and Planetary Science Letters, 241(3-4): 477-492.

D'Almeida, G.A., Koepke, P. and Shettle, E.P., 1991: Atmospheric aerosols: global climatology and radiative characteristics. Deepak publishing, QC882.42-D148.

Dansgaard, W., Johnsen, S.J., Clausen, H.B., Dahl-Jensen, N.S., Gundestrup, N.S., Hammer, C.U., Hvidberg, C.S., Steffensen, J.P., Sveinbjornsdottir, A.E., Jouzel, J. and Bond, G., 1993: Evidence for general instability of past climate from a 250-kyr ice-core record., Nature, 364: 218-220.

DeBaar, H.J.W., Bacon, M.P. and Brewer, P.G., 1985: Rare earth elements in the Pacific and Atlantic Oceans, Geochimica et Cosmochimica Acta 49: 1943-1959.

De Baar, H. J. W., and Boyd, P.W., 2000: The role of iron in plankton ecology and carbon dioxide transfer of the global oceans., In (Hanson, R.B. et al. Eds.) The Dynamical Ocean Carbon Cycle: A Midterm Synthesis of the Joint Global Ocean Flux Study., edited by, p. 61-140, Cambridge University Press, Cambridge.

De Baar, H.J.W., Boyd, P.W., Coale, K.H., Landry, M.R., Tsuda, A., Assmy, P., Bakker, D.C.E., Bozec, Y., Barber, R.T., Brzezinski, M.A., Buesseler, K.O., Boyé, M., Croot, P.L., Gervais, F., Gorbunov, M.Y., Harrison, P.J., Hiscock, W.T., Laan, P., Lancelot, C., Levasseur, M., Marchetti, A., Millero, F.J., Nishioka, J., Nojiri, Y., van Oijen, T., Riebesell, U., Rijkenberg, M.J.A., Saito, H., Takeda, S., Timmermans, K.R., and Veldhuis, M.J.W., 2005: Synthesis of 8 iron fertilization experiments: from the Iron Age in the Age of Enlightment. Journal of Geophysical Research, C09S16, doi: 10.1029/2004JC002601, 110: 1-24.

De Baar, H., et al., 2005: Synthesis of Iron Fertilization Experiments: from the Iron Age in the Age of Enlightenment., Journal of Geophysical Research (Oceans), 110, doi: 10.1029/2004JC002601.

DeMenocal, P.B., 2001: Cultural responses to climate change during the late Holocene, Science 292: 667-673. 
Dolgov, Y.A., Vasilyev, N.V., Shugurova, N.A., et al., 1971: Chemical composition of silicate spherules from peat near the impact point of the Tunguska Meteorite. Transactions of the USSR Academy of Sciences; Earth Science Sections, 200: 212-214.

Duce, R. A., Liss, P.S., Merrill, J.T., Atlas, E.L., Buat-Menard, P., Hicks, B.B., Miller, J.M., Prospero, J.M., Arimoto, R., Church, T.M., Ellis, W., Galloway, J.N., Hansen, L., Jickells, T.D., Knap, A.H., Reinhardt, K.H., Schneider, B., Soudine, A., Tokos, J.J., Tsunogai, S., Wollast, R., and Zhou, M.., 1991. The atmospheric input of trace species to the world ocean. Global Biogeochemical Cycles 5: 193-259.

Duce, R. A., and Tindale, N.W., 1991: Atmospheric transport of iron and its deposition in the ocean. Limnology and Oceanography, 36: 1715-1726.

Fisher, D.A. and Koerner, R.M., 2003: Holocene ice-core climate history - a multi-variable approach. In Macay, A. et al. (Eds): Global change in the Holocene, Arnold, London, p.281-293.

Franzén, L., 1985: Peat in Sweden - a method to calculate the resources. Thesis, GUNI Rapport 21, $241 \mathrm{~s}$.

Franzén, L.G., 1990: Transport, deposition and distribution of marine aerosols over southern Sweden during dry westerly storms. AMBIO, 19: 180-188.

Franzén, L.G., 1992: Can Earth afford to lose the wetlands in the battle against the increasing greenhouse effect. IPC Proceedings of the 9th International Peat congress, Uppsala, Sweden 1992. International Peat Journal Special Issue Vol 1(3): 1-18.

Franzén, L. G., 1994: Are wetlands the key to the ice age cycle enigma? AMBIO 23(4-5): 300308.

Franzén, L.G. and Chen, D., 1995: Peat-forming wetlands and the Quaternary palaeo-climate development. Abstract, Terra Nostra 2: 84.

Franzén, L.G., Chen, D. and Klinger, L.F.,1996: Principles for a climate regulation mechanism during the late Phanerozoic era, based on carbon fixation in peatforming wetlands. AMBIO 25(7): 435-442.

Franzén, L.G., 1997: Reply to Rodhe's and Malmer's (RM) Comments on Franzén et al. "Principles for a climate regulation mechanism during the late Phanerozoic era, based on carbon fixation in peatforming wetlands". AMBIO, 26(3): 188-189.

Franzén, L.G., 1998: Vilken roll spelar torven i det globala klimatsystemet? Kungliga Skogso. Lantbruksakademins Tidskrift 137(8): 89-96 (In Swedish).

Franzén, L.G., 2001: Global Warming and the Peatland/Ice Age Hypothesis. Proceedings of the 1st International Conference on Global Warming and the Next Ice Age, Halifax, Canada.

Franzén, L., 2002: Tillväxtdynamik hos några myrar i södra Sverige - samt några noteringar om torvmarker som arkiv över atmosfärshändelser under holocen. Stiftelsen Svensk Torvforskning Projektrapport 47: 1-43 (In Swedish).

Franzén, L., 2004: Vädret för 5000 år sedan - vad rör det oss? In YMER Yearbook 2004 "Solen, klimatet, människan", pp 130-155. (In Swedish).

Franzén, L.G., 2006: Mineral matter, and major and trace elements, in raised bog peat. A case study from south Sweden, Ireland and Tierra del Fuego, Argentina. In Martini, I.P., Martinez Cortizas A., and Chesworth, W. (Eds.) Peatlands: evolution and records of environmental and climatic changes, Elsevier, p.241-269.

Franzén L.G., 2006: Increased rate of decomposition of subsurface peat in temperate raised bogs - are peatlands still net sinks of carbon? Mires and Peat, Vol 1: http://www.miresand-peat.net/map01/map_1_3.htm

Fredriksson, D., 1996: Peat resources in Sweden In: Lappalainen, E. (Ed.), Global peat resources. International Peat Society, Jyskä, Finland, pp 137-144. 
Fung, I.Y., Meyn, S.K., Tegen, I., Doney, S.C., John, J.G. and Bishop, J.K.B., 2000: Iron supply and demand in the upper ocean. Global Biogeochemical Cycles, 14: 281-295.

Gabric, A.J., Cropp, R.A., Hirst, C. and Marchant, H.J., 2003: The response of dimethylsulphide production to simulated warming in the eastern Antarctic Southern Ocean, Tellus, 55B: 966-981.

Gao, Y., Kaufman, Y.J., Tanre, D. Kolber, D. and Falkowski, P.G., 2001: Seasonal distributions of aeolian iron fluxes to the global ocean. Geophysical Research Letters, 28, 29-32.

Gasse, F., 2000: Hydrological changes in African tropics since the last Glacial Maximum. Quaternary Science Reviews 19: 189-211.

Grafenstein von, U., H. Erlenkeuser, H. Muller, J., Jouzel, J. and Johnsen, S.J., 1998: The cold event 8,200 years ago documented in oxygen isotope records of precipitation in Europe and Greenland. Climate Dynamics, 14: 73-81.

Granlund, E., 1932: De svenska högmossarnas geologi. Sveriges Geologiska Undersökning Ser.C, N:o 373: 1-193 (in Swedish).

Haas, J.N., Richoz, I., Tinner, W. and Wick, L., 1998: Synchronous Holocene climatic oscillations recorded on the Swiss Plateau and at timberline in the Alps. The Holocene 8(3): 301-309.

Hagen, E.H., Koeberl, C. and Faure, G., 1990: Extraterrestrial spherules in glacial sediment, Beardmore Glacier area, Transatlantic Mountains. Contribution to Antarctic Research I, Antarctic Research Series, 50: 19-24.

Hamilton, W. D., and Lenton, T.M., 1998: Spora and Gaia: how microbes fly with their clouds., Ethology, Ecology and Evolution, 10:1-16.

Heiri, O., Lotter, A.F., Hausmann, S. and Kienast, F., 2003: A chironomid-based Holocene summer air temperature reconstruction from the Swiss Alps. The Holocene 13(4): 477484.

Holzhauser, H., Magny, M. and Zumbühl, H.J., 2005: Glacier and lake-level variations in west-central Europe over the last 3500 years. The Holocene 15(6): 789-801.

Honjo, S., 1996: Fluxes of particles to the interior of the open oceans, In: Ittekkot, V., Schäfer, P., Honjo, S., and Depetris, P.J. (Eds.), Particle Flux in the Ocean, John Wiley \& Sons Ltd, p. 91-113

Hunten, D.M., Turco, R.P. and Toon, O.B., 1980: Smoke and dust particles of meteoric origin in the mesosphere and stratosphere, Journal of the Atmospheric Sciences 37(6): 13421357.

Irwin, H., Curtis, C. and Coleman, M., 1977: Isotopic evidence for source of diagenetic carbonates formed during burial of organic rich sediments. Nature, 269: 209-213.

Isomäki, R., 2002: Seeded by cosmic dust. New Scientist (letter) 12 Oct. 2002 p. 26.

Jickells, T., 2006: The role of air-sea exchange in the marine nitrogen cycle Biogeosciences Discuss. 3:183-210, 2006 www.biogeosciences-discuss.net/3/183/2006/

Johansson, I., 1976: Hydrologiska undersökningar inom myrkomplexet Komosse. Statens Naturvetenskapliga Forskningsråd, KTH. (In Swedish)

Johnson, K.S., 2001: Iron supply and demand in the upper ocean: is extraterrestrial dust a significant source of bioavailable iron? Global Geochemical Cycles 15: 61-63.

Kane, T.J. and Chester S.G., 1993: Lidar observations of the meteoric deposition of mesospheric metals. Science, 259: 1297-1300.

Karlén, W., Bodin, A., Kuylenstirna, J. and Näslund, J.-O., 1995: Climate of Northern Sweden during the Holocene. In Finkl, Jnr, C.W. (Ed.) Holocene Cycles: Climate, Sea Levels and Sedimentation, Journal of Coastal Research Special Issue No.17: 49-54.

Kennett, J.P., Cannariato, K.G., Hendy, I.L. and Behl, R.J., 2000: Carbon Isotopic Evidence for Methane Hydrate Instability During Quaternary Interstadials. Science 288(5463): 
$128-133$.

Kerschner, H., Hertl, A., Gross, G., Ivy-Ochs, S. and Kubik, P.W., 2006: Surface exposure dating of moraines in the Kromer valley (Silvretta Mountains, Austria) - evidence for glacial response to the $8.2 \mathrm{ka}$ event in the Eastern Alps? The Holocene 16(1): 7-15.

Kiene, R. P., Linn, L.J. and Bruton, J.A., 2000: New and important roles for DMSP in marine microbial communities. Journal of Sea Research, 43: 209-224.

Klinger, L.F., 1990: Global patterns in community succession 1. Bryophytes and forest decline. Memoirs of the Torrey Botanical Club 24: 1-50.

Klinger, L.F., 1991: Peatland formation and ice ages: A possible Gaian mechanism related to community succession. In Schneider, S.H. and Boston, P.J. (Eds.) Scientists on Gaia, MIT Press, Cambridge p. 246-255.

Klinger, L.F., Taylor, J.A. and Franzén, L.G.,1996: The potential role of peatland dynamics in ice-age initiation. Quaternary Research, 45: 89-92.

Klitgaard-Kristensen, D., Sejrup, H.P. Haflidason, H., Johnsen, S. and Spurk, M., 1998: The short cold period 8,200 years ago documented in oxygen isotope records of precipitation in Europe and Greenland. Journal of Quaternary Sciences, 13: 165-169.

Kofler, W., Krapf, V., Oberhuber, W. and Bortenschlager, S., 2005: Vegetation responses to the 8200 cal. BP cold event and long-term climatic changes in the Eastern Alps: possible influence of solar activity and North Atlantic freshwater pulses. The Holocene 15(6): 779-788.

Kohfeld, K. E., Le Quere, C., Harrison, S.P. and Anderson, R.F., 2005: Role of marine biology in glacial-interglacial $\mathrm{CO}_{2}$ cycles, Science, 308: 74-78.

Kolesnikov, E.M., Stepanov, A.I., Goridko, E.A. and Kolesnikova, N.V., 1998: Element and isotopic anomalies in peat from the Tunguska explosion (1908) area are probably traces of cometary matter. Meteoritics and Planetary Science, 33: A85.

Korhola, A., 1992: Mire inducation, ecosystem dynamics and lateral extension on raised bogs in the southern coastal area of Finland, Fennia 170: 25-94.

Korhola, A., 1994: Radiocarbon evidence for rates of lateral expansion in raised mires in southern Finland, Quaternary Research 42: 299-307.

Korhola, A.A., 1995: Holocene climatic variations in southern Finland reconstructed from peat-initiation data. The Holocene, 5: 43-58.

Kuzmin, G.F., 1994: To the balance of peat winning and recreation. All-Union Research Institute for Peat Industry St.Petersburg, Russia. Internal Report 8.

Laberyrie, L., Cole, J., Alverson, K. and Stocker, T., 2003: The history of climate dynamics in the Late Quaternary. In Alverson, et al. (Eds), Paleoclimate, global change and the future, Springer, p.33-61.

Lamb, A.L., Leng, M.J., Lamb, H.F. and Mohammed, M.U., 2000: A 9000-year oxygen and carbon isotope record of hydrological change in a small Ethiopian crater lake. The Holocene 10(2): 167-177.

Legrand, M., Hammer, C., De-Angelis, M., Savarino, J. Delmas, R., Clausen, H. and Johnsen, S.J., 1997: Sulfur-containing species (methanesulfonate and $\mathrm{SO}_{4}$ over the last climatic cycle in the Greenland Ice Core Project (central Greenland) ice core. Journal of Geophysical Research, 102(C12): 26663-26679.

Leuschner, H.H., Sass-Klaassen, U., Jansma, E., Baillie, M.G.L. and Spurk, M., 2002: Subfossil European bog oaks: population dynamics and long-term growth depressions as indicators of changes in the Holocene hydro-regime and climate. The Holocene 12(6): 695-706.

Levasseur, M., Scarratt, M.C., Michaud, S., Merzouk, A., Wong, C.S., Arychuk, M., Richardson, W., Rivkin, R.B. Hale, M., Wong, E., Marchetti, A. and Kiyosawa, H., 2006: DMSP and DMS dynamics during a mesoscale iron fertilization experiment in the 
Northeast Pacific - Part I: Temporal and vertical distributions. Deep-Sea Research II, 53: 2353 - 2369.

Lin, X., and Chameides, W.L., 1993: CCN formation from DMS oxidation without $\mathrm{SO}_{2}$ acting as an intermediate. Geophysical Research Letters, 20: 579-582.

Lode, E., Sagris, V. and Ilomets, M., 2001: GIS estimation of mire massif development. In: Lode, E. Natural mire hydrology in restoration of peatland functions. Silvestria 234.

Lode, E., 2002: GIS estimation of mire massif development. Natural mire hydrology in restoration of peatland functions, Studia Forestalia Suecica 205: 30.

Long, A.J., Roberts, D.H. and Dawson, S., 2006: Early Holocene history of the west Greenland Ice Sheet and the GH-8.2 event. Quaternary Science Reviews 25: 904-922.

Lundqvist, G., 1955: Myrar (Peat land): Atlas över Sverige 41-42, Stockholm 1955 (In Swedish with extended English summary).

Magny, M., Bégeot, C., Guiot, J., Marguet, A. and Billaud, Y., 2003: Reconstruction and palaeoclimatic interpretation of mid-Holocene vegetation and lake-level changes at Saint-Jorioz, French Pre-Alps. The Holocene 13(2): 265-275.

Malmström, C., 1932: Om faran för skogsmarkens försumpning i Norrland. Meddelanden från Statens Skogsförsöksanstalt 26: 1-126. (In Swedish).

Manabe, S. and Bryan, K. Jr., 1985: $\mathrm{CO}_{2}$-induced change in a coupled ocean-atmosphere model and its paleoclimatic implications. Journal of Geophysical Research 90: 1168911707.

Marchetti, A., Juneau, P., Whitney, F.A., Wong, C.S. and Harrison, J.P., 2006: Phytoplankton processes during a mesoscale iron enrichment in the NE subarctic Pacific: Part IINutrient utilization. Deep-Sea Research II, 53: 2114-2130

Martin, J.H., Fitzwater, S.E. and Gordon, R.M., 1990: Iron deficiency limits phytoplankton growth in Atlantic waters, Global Biogeochemical Cycles 4: 5-12.

Martin, J., 1990: Glacial-interglacial $\mathrm{CO}_{2}$ change: the iron hypothesis. Paleoceanography, 5: $1-13$.

Mithen, S.J., 2003: After the Ice: A Global Human History, 20,000-5000 BC. Weidenfeld and Nicolson, London.

Morel, F.M.M., Hudson, R.J.M. and Price, N.M., 1991: Limitation of productivity by trace metals in the sea. Limnol. Oceanogr. 36: 1742-1755.

Morrill, C., Overpeck, J. T. and Cole, J. E., 2003: A synthesis of abrupt changes in the Asian summer monsoon since the last deglaciation. The Holocene 13: 465-476.

McLennan, S.M. and Taylor, S.R., 1981: Role of subducted sediments in island-arc magmatism: constraints from REE patterns. Earth and Planetary Science Letters, 54: 423-430.

Murray, S. and Renard, A.F., 1891: Report on Scientific Results from Voyage H.M.S. Challenger 7. Neill and Co., 327 p.

Muscheler, R., Beer, J. and Vonmoos, M., 2004: Causes and timing of the $8200 \mathrm{yr}$ BP event inferred from comparison of the GRIP ${ }^{10} \mathrm{Be}$ and the tree ring $\Delta^{14} \mathrm{C}$ record. Quaternary Science Reviews 23: 2101-2111.

Nazarov, M.A., Korina, M.I., Kolesov, G.M. and Vasilyev, N.V., 1983: The Tunguska event; mineralogical and geochemical data. Proceedings of the Lunar and Planetary Science Conference 14, Part 2, p. 548-549.

Nesje, A., Bjune, A.E., Bakke, J., Dahl, S.O., Lie, Ø. and Birks, H.J.B., 2006: Holocene palaeoclimate reconstructions at Vanndalsvattnet, western Norway, with particular reference to the $8200 \mathrm{cal}$. Yr BP event. The Holocene 16(5): 717-729.

Nott, J., Bryant, E. and Price, D., 1999: Early-Holocene aridity in tropical northern Australia. The Holocene 9(2): 231-236. 
Olvmo, M., Lidmar-Bergström, K., Ericson, K., and Bonow, J.M., 2005: Saprolite remnants as indicators of pre-glacial landform genesis i southeast Sweden. Geografiska Annaler 87A (3): 447-460.

Osvald, H., 1923: Die Vegetation des Hochmoores Komosse. Svenska Växtsociologiska Sällskapets Handlingar I, Uppsala, 436 s. (In German)

Pederstad, K. and Aagaard, P., 1985: Interstitial waters and diagenetic changes of marine sediments from Oslofjord and Skagerrak. Norsk Geologisk Tidskrift, 4: 287-299.

Peristykh, A. N., and Damon, P.E., 2003: Persistence of the Gleissberg 88-year solar cycle over the last $\sim 12,000$ years: Evidence from cosmogenic isotopes. Journal of Geophysical Research, 108, doi:10.1029/2002JA009390.

Pettersson, H. and Fredriksson, K., 1958: Magnetic spherules in deep-sea deposits. Pacific Science, 12: 71-81.

Pilcher, J.R. and Hall, V.A., 1992: Towards a tephrochronology for the Holocene of the north of Ireland. Holocene 2(3): 255-259.

Pisaric, M.F.J., Holt, C., Szeicz, J.M., Karst, T. and Smol, J.P., 2003: Holocene treeline dynamics in the mountains of northeastern British Columbia, Canada, inferred from fossil pollen and stomata. The Holocene 13(2): 161-173.

Plane, J. M. C., Murray, B.J., Chu, X. and Gardner, C.S., 2004. Removal of meteoric iron on polar mesospheric clouds. Science 304: 426-428.

Post, L von, 1927: Beskrivning till översiktskarta över södra Sveriges myrmarker. Sveriges Geologiska Undersökning Ser Ba 11. (In Swedish)

Prasad, S., Brauer, A., Rein, B. and Negendank, J.F.W., 2006: Rapid climate change during the early Holocene in western Europe and Greenland. The Holocene 16(2): 153-158.

Prospero, J. M., Ginoux, P., Torres, O., Nicholson, S.E. and Gill, T.E., 2002: Environmental characterisation of global sources of atmospheric soil dust identified with the NIMBUS7 TOMS absorbing aerosol product., Reviews of Geophysics (40(1): 1002, doi. 10.1029/2000RG000095

Rahmstorf, S., 2003: Timing of abrupt climate change: a precise clock., Geophysical Research Letters, 30, doi: 10.1029/2003GL017115.

Ramrath, A., Sadori, L. and Negendank, J.F.W., 2000: Sediments from Lago di Mezzano, central Italy: a record of Lateglacial/Holocene climatic variations and anthropogenic impact. The Holocene 10: 87-96.

Raukas, A., 1997: An attempt to use microimpactites in establishing the age of impact events on the example of the Kaali crater field (Estonia), Sphaerula 1(1): 32-41.

Raukas, A., Tiirmaa, R., Kaup, E. and Kimmel, K., 2001: The age of Ilumetsa meteorite craters in Southeast Estonia. Meteoritics and Planetary Science, 36: 1507-1514

Renberg, I., Brännvall, M.-L., Bindler, R. and Emteryd, O., 2000: Atmospheric lead pollution history during four millennia (2000 BC to 2000 AD) in Sweden. Ambio 29(3): 150-156.

Renberg, I., Bindler, R. and Brännvall, M.-L., 2001: Using the historical atmospheric leaddeposition record as a chronological marker in sediment deposits in Europe. The Holocene, 11(5): 511-516.

Rietmeijer, F.J.M. and Jenniskens, P., 1998: Recognizing Leonid meteoroids among the collected stratospheric dust, Earth, Moon and Planets 82-83: 505-524.

Robinson, S.A., Black, S., Sellwood, B.W. and Valdes, P.J. 2006: A review of palaeoclimates and palaeoenvironments in the Levant and Eastern Mediterranean from 25,000 to 5000 years BP: setting the environmental background for the evolution of human civilisation Quaternary Science Reviews 25: 1517-1541.

Rohling, E.J. and Pälike, H., 2005: Centennial-scale climate cooling with a sudden cold event around 8,200 yrs ago. Nature, 434: 975-979. 
Rosén, P., Segerström, U., Erikson, L. Renberg, I. and Birks, H.J.B., 2001: Holocene climatic change reconstructed from diatoms, chrinomids, pollen and near-infrared spectroscopy at an alpine lake Sjuodjijaure, in northern Sweden. The Holocene 11(5): 551-562.

Salinger, M.J. and McGlone, M.S., 1989: New Zealand Climate - The past two million years. The New Zealand Climate report 1990, Royal Society of New Zealand, Wellington, p.13-17.

Shaviv, N.J, and Veizer, J., 2003: Celestial driver of Phanerozoic climate?: GSA Today,13(7): 4-10, doi: 10.1130/1052-5173(2003)0132.0.CO;2.

Schulz, K.G., Zondervan, I., Gerringa, L.J.A., Timmermans, K.R., Veldhuis, M.J.W. and Riebessel, U., 2004: Effect of trace metal availability on cocolithophorid calcification. Nature 430: 673-676.

Seftigen, K., 2007: Potential lateral expansion of wetlands in the county of Västra Götaland, Sweden. Earth Sciences Centre, Göteborg University Ser. C 80, 19 p.

Seibold, E. and Berger, W.H., 1982: The sea floor - an introduction to marine geology. Springer, New York, 288 p.

Shakesby, R.A., Matthews, J.A. and Winkler, S., 2004: Glacier variations in Breheimen, southern Norway: relative-age dating of Holocene moraine complexes at six highaltitude glaciers. The Holocene 14(6): 899-910.

Shuman, B., Huang, Y., Newby, P., and Wang, Y., 2006: Compound-specific isotopic analyses track changes in seasonal precipitation regimes in the Northeastern United States at ca 8200 cal yr BP. Quaternary Science Reviews 25: 2992-3002

Simo, R., 2001: Production of atmospheric sulfur by oceanic plankton: biogeochemical, ecological and evolutionary links. Trends in Ecology and Evolution, 16, 287-294.

Sønstegard, E. and Mangerud, J., 1977: Stratigraphy and dating of Holocene gully sediments in Os, western Norway. Norsk Geologisk Tidskrift 57: 313-346.

Stager, J.C. and Mayewski, P.A., 1997: Abrupt Early to Mid-Holocene Climatic transition registered at the Equator and the Poles. Science, 276: 1834-1836.

Starkel, L., 1984: Abrupt climatic changes in continental deposits. In Mörner, N.-A. and Karlén, W. (Eds.) Climatic Changes on a Yearly to Millenial Basis, D.Reidel Publ. Co. p.135-146.

Starkel, L., Pazdur, A., Pazdur, M.F., Wicic, B. and Wieckowski, K., 1996: Lake-level and groundwater-level changes in the Lake Gosciaz area, Poland: palaeoclimatic implications. The Holocene 6(2): 213-224.

Staubwasser, M. and Weiss, H., 2006: Holocene climate and cultural evolution in late prehistoric-early historic West Asia. Quaternary Research 66: 372-387.

Street-Perrott, F.A. and Perrott, R.A., 1990: Abrupt climate fluctuations in the tropics: the influence of Atlantic ocean circulation. Nature, 343: 607-612.

Stuiver, M. and Reimer, P.J., 1993: CALIB Radiocarbon Calibration Program, Radiocarbon, 35: 215-230.

Sun, B. and Bradley, R.S., 2002: Solar influences on cosmic rays and cloud formation: A reassessment. Journal of Geophysical Research, 107(D14), 10.1029/2001JD000560.

Sunda, W., Kieber, D.J., Kiene, R.P. and Huntsman, S., 2002: An antioxidant function for DMSP and DMS in marine algae. Nature, 418: 317-320.

Svensmark, H. and Friis-Christensen, E., 1997: Variation of cosmic ray flux and global cloud coverage - a missing link in solar-climate relationships. Journal of Atmospheric and Solar Terrestrial Physics 59 (11): 1225-1232.

Svensmark, H., 2007: Cosmoclimatology: a new theory emerges. Astronomy and Geophysics 48(1): 18-24.

Taylor, P.L., Nusbaum, R.L., Fronabarger, A.K, Katuna, M. P., Summer, N. et al., 1996: Magnetic spherules in coastal plain sediments, Sullivan's Island, South Carolina, USA. 
Meteoritics and Planetary Science, 31: 77-80.

Thomas, E.R., Wolff, E.W., Mulvaney, R, Steffensen, J.P, Johnsen, S.J., Arrowsmith, C, White, J.W.C., Vaughn, B. and Popp, T., 2007: The 8.2 ka event from Greenland ice cores. Quaternary Science Reviews 26: 70-81

Tolf, R., 1893: Komosse, Svenska Mosskulturföreningens Tidskrift 1893, Jönköping, p.531537 (In Swedish).

Turner, S. M., Nightingale, P.D., Spokes, L.J., Liddicoat, M.I. and Liss, P.S., 1996: Increased dimethylsulphide concentrations in sea water from in situ iron enrichment. Nature, 383, 513-517.

Turner, S. M., Harvey, M., Law, C.S., Nightingale, P.D. and Liss P.S., 2004: Iron-induced changes in oceanic sulfur biogeochemistry. Geophysical Research Letters, 31, doi: 10.1029/2004GL020296.

Turunen, C. and Turunen, J., 2003: Development history and carbon accumulation of a slope bog in oceanic British Columbia, Canada. The Holocene 13(2): 225-238.

Vasilyev, N.V., Bronskiy, B.I. and Demin, D.V. 1971: Silicate spherules in peat near the point of impact of the Tunguska Meteorite. Transactions of the USSR Academy of Sciences; Earth Science Sections, 199: 212-214

Verreccia, E.P., Freytet, P., Verrecchia, K.E. and Dumont, J.-L., 1995: Spherulites in calcrete laminar crusts: biogenic $\mathrm{CaCO}_{3}$ precipitation as a major contributor to crust formation. Journal of Sedimentology Research, A65: 690-700.

Veski, S., Heinsalu, A., Kirimae, K., Poska, A. and Saarse, L., 2001: Ecological catastrophe with the impact of the Kaali meteorite about 800-400 B.C. on the island of Saaremaa, Estonia. Meteoritics and Planetary Science, 36: 1367-1375.

Wagner, G., Beer, J. J. Masarik, J. Muscheler, R. Kubik, P.W. Mende, W. Laj, C. Raisbeck, G.M. and Yiou, F., 2001: Presence of solar de Vries cycle ( 205 years) during the last ice-age., Geophysical Research Letters, 28: 303-306.

Watson, A., Bakker, D.C.E., Ridgwell, A.J., Body, P.W. and Law, C.S., 2000: Effect of iron supply on Southern Ocean $\mathrm{CO}_{2}$ uptake and implications for glacial atmospheric $\mathrm{CO}_{2}$, Nature, 407: 730-733.

Weiss, H. and Bradley, R.S., 2001: What Drives Societal Collapse? Science 291: 609-610.

Weninger, B., Alram-Stern, E., Bauer, E., Clara, L. Danzeglocke, U., Jöris, O., Kubatzki, C., Rollefson, G., Todorova, H. and Van Andel, T. 2006: Climate forcing due to the 8200 cal yr BP event observed at Early Neolithic sites in the eastern Mediterranean. Quaternary Research 66: 401-420.

Wick, L. and Tinner, W., 1999: Vegetation changes and timberline fluctuations in the Central Alps as indicators of Holocene climate oscillations. Arctic and Alpine Research, 29: 445-458.

Wick, L., Lemcke, G. and Sturm, M., 2003: Evidence of Late-Glacial and Holocene climatic change and human impact in eastern Anatolia: high-resolution pollen, charcoal, isotopic and geochemical records from the laminated sediments of Lake Van, Turkey. The Holocene 13(5): 665-675.

Winckler, G., and Fischer, H., 2006: 30,000 years of cosmic dust in Antarctic ice., Science, 313: 491.

Wolfe, G. V., Steinke, M. and Kirst, G.O., 1997: Grazing-activated chemical defence in a unicellular marine alga. Nature, 387: 894-897.

Wong, C.S., Timothy, D.A., Law, C.S., Nojiri, Y. Xie, L., Wong, S.K.E. and Page, J.S., 2006: Carbon distribution and fluxes during the SERIES iron fertilization experiment with special reference to the fugacity of carbon dioxide $\left(\mathrm{fCO}_{2}\right)$. Deep-Sea Research II, 53: 2053-2074.

Yu, X., Zhou, W., Franzén, L.G., Xian, F., Cheng, P. and Jull, A.J.T., 2006: High-resolution 
peat records for Holocene monsoon history in the eastern Tibetan Plateau, Science in China, Ser. D - Earth Sciences 49(6): 615-621.

Zbik, M. and Gostin, V.A., 1995: Morphology and internal structure of Antarctic cosmic dust spherules: possible links to meteorite fusion crusts. Proceedings of the National Institute of Polar Research Symposium on Antarctic Meteorites, 8: 339-351.

Appendix. The text freely moves along different peatland terms that might not be known to the general reader. The definitions vary from one country to another and also between different branches of interest. Internationally a ground is classified as a peatland if the peat exceeds $30 \mathrm{~cm}$ above the mineral substratum. The term wetland includes all grounds that host a hydrophile vegetation, whereas the term mire includes peatforming wetlands. The mires are divided into two main categories i.e. fens and bogs. Whereas bogs, or ombrotrophic mires are totally dependent on water and nutrient supply from the atmosphere the fens, or minerotrophic mires, are fed by this in addition to nutrients and water from surrounding mineral soils and/or watersheds. 